\title{
FY 2012 INL Self Assessment Report
}

October 2012

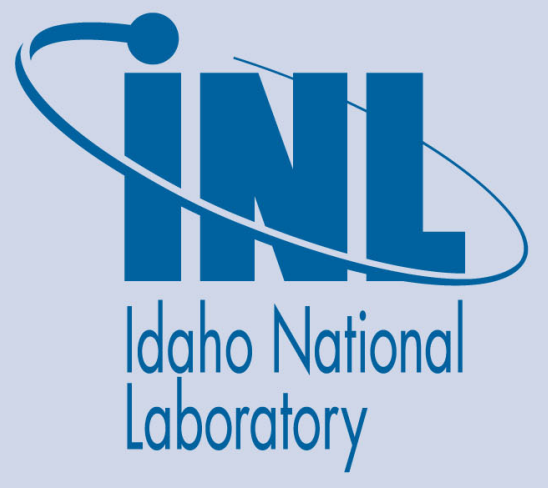

The INL is a U.S. Department of Energy National Laboratory operated by Battelle Energy Alliance 
INL/EXT-12-27404

\section{FY 2012 INL Self Assessment Report}

October 2012

\section{Idaho National Laboratory \\ Idaho Falls, Idaho 83415}

http://www.inl.gov

Prepared for the

U.S. Department of Energy

Under DOE Idaho Operations Office

Contract DE-AC07-05ID14517 
FY 2012 INL

Self Assessment Report

October 2012
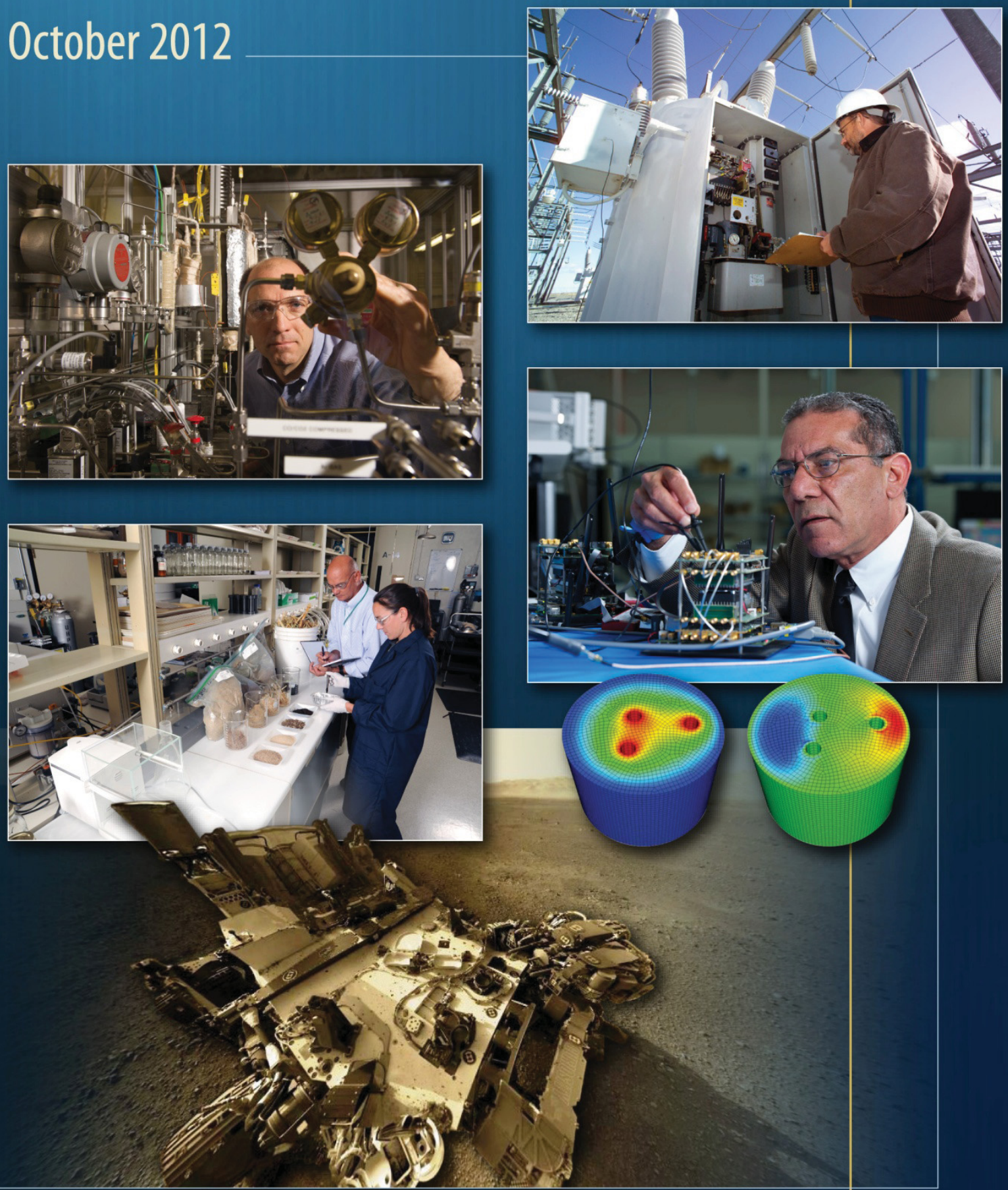

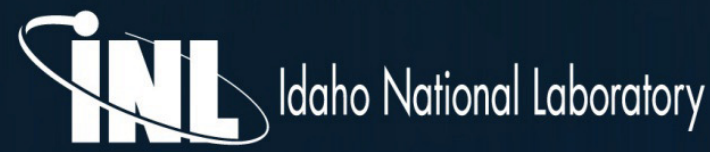





\section{EXECUTIVE SUMMARY}

Idaho National Laboratory (INL) operated during Fiscal Year 2012 (FY12) against a backdrop of unprecedented uncertainty. While the early years of the current contract brought to INL resources and opportunities well beyond those envisioned by Department of Energy (DOE) in 2004, FY12 confirmed that reductions first seen in FY11 were the start of a multi-year negative trend in available resources. After 5 years of average annual business growth of roughly $10 \%$, INL, along with many of its customers, faced budget reductions on a scale roughly equivalent to the previous rate of growth.

INL's plans felt the impact of low natural gas prices, a slow domestic economic recovery, and the 2011 Fukushima Daiichi events that slowed momentum in the planned nuclear power expansion, called into question the future of several nuclear power markets, and defined a new set of operational and safety priorities demanding the attention of domestic plant operators. Compounding the challenges, a series of operational events in INL nuclear facilities belied the generally positive safety trends, led management to institutional self-examination, prompted external scrutiny and investigations, and drove a series of management actions that created further budgetary and programmatic perturbations.

Ultimately, rather than risk the possibility of an event with more far reaching consequences to employees and the lab, INL management took the decision at mid-year to cease work at MFC - to stand down operations until they could assure that operations could be conducted safely at minimal risk to employees and the public. INL management took this decision knowing it would result in missed milestones, further compound financial challenges, potentially cloud customer and partner relationships, generate negative near-term publicity, and, as a consequence, have a negative impact on DOE's assessment of our performance. It came down to basics - the decision reflected the uncompromising commitment of INL management to safety in the workplace and our insistence on accountability as a fundamental value of the institution.

However, there were many notable developments that point to continued progress toward achieving the vision for INL. The FY12 self-assessment accounts for the many accomplishments that benefit our customers, employees, partners across the globe, our host community, and the DOE mission. The assessment also acknowledges INL performance shortcomings that, while significant and undesirable in and of themselves, stimulated commitments and actions to make the lab a stronger institution in the long run.

\section{Impactful Science and Technology}

Throughout the year, INL continued to make critical contributions in science and technology (S\&T). All of INL's technical organizations made contributions to the nuclear energy mission as well as applying research, analysis, operations, and technical logistics capabilities across a broad range of challenges, as a sole provider or in collaboration with industry, academic, national lab, and international partners. S\&T advancements or engagements of note include:

- Broad use of MOOSE-BISON-MARMOT suite of codes by national laboratories, universities, and industry to advance the understanding of nuclear fuel performance. As a testament to INL's success, on July 23, 2012, 
President Barack Obama named INL scientist Derek Gaston, lead developer for MOOSE, as one of 96 recipients of the Presidential Early Career Awards for Scientists and Engineers.

- The Light Water Reactor Sustainability program continued to have national significance with strong interest and participation by the Nuclear Regulatory Commission (NRC) and industry:

- INL led a series of pilot projects at commercial reactor sites and in the INL Human Systems Simulation Laboratory that demonstrated digital technologies to modernize legacy information, instrumentation, and control systems. In July, INL was notified that one of the technologies demonstrated would be implemented in nine Exelon plants.

- INL demonstrated its approach to Risk Informed Safety Margin Characterization using ATR, demonstrating how thermal-hydraulics and probabilistic safety calculations could be integrated and used to quantify margin management strategies.

- INL wrote the pre-decisional draft, "Development of Light Water Reactor Fuels with Enhanced Accident Tolerance - Report to Congress." This report has been submitted to DOE Nuclear Energy (NE) for their review and ultimate delivery to Congress.

- INL initiated a 10-year collaboration with South Korea to jointly explore fuel cycle options, including electrochemical recycling, used fuel storage, and corresponding safeguards activities.

- INL fueled, tested, and delivered the multi-mission thermo-electric generator (MMRTG) that is powering the Rover Curiosity in its mission to Mars.

- INL initiated a cooperative research and development effort with TerraPower to further the design of the traveling wave nuclear reactor concept; the partner committed nearly $\$ 8 \mathrm{M}$ of funds for this multi-year collaboration.

- $\quad$ The Advanced Test Reactor (ATR) National Scientific User Facility (NSUF) continued to support collaborations with international research facilities including:

- INL-developed Higher Temperature Irradiation Resistant Thermocouples (HTIR-TCs) were shipped to the Halden Reactor in Norway for irradiation testing

- Specimens irradiated in the first University of California Santa Barbara (UCSB) experiment were shipped to Oxford University for further postirradiation examination (PIE) work

- Work continued on analysis of material for Atomic Energy of Canada Limited (AECL).

- During FY 2012, INL staff received recognition from the Secretary of Energy and National Nuclear Security Administration (NNSA) senior leaders for multiple accomplishments:

- Removing special nuclear material from the former Soviet Union plutonium production facility $(\mathrm{BN}-350)$ 
- Converting the Mexican ININ research reactor to enable the U.S. to meet commitments from the Trilateral Announcement - April 2010 Washington Nuclear Summit

- Leading an operation with Ukraine to remove $128 \mathrm{~kg}$ of highly enriched uranium (HEU) from two Ukrainian facilities prior to the 2012 Nuclear Security Summit.

- INL leadership and innovation in wireless communications was nationally recognized by receiving an R\&D 100 award for the Wireless Spectrum Communications (WSComm) technology. WSComm was originated under laboratory-directed research and development (LDRD) funding and developed in collaboration with University of Utah researchers. It offers potential solutions to expand the efficient use and availability of the radio frequency spectrum, delivering multimedia mobile services.

- INL conducted a highly successful, full-scale test using the lab's electric grid to determine the effects of Geomagnetic Induced Currents (such as those generated by a solar storm) coupled onto the grid. This was a follow-up test to a first-ever transformer test performed last year. The follow-up test included the introduction of multiple mitigation strategies under different load and current conditions, and the data collected will greatly advance the nation's understanding of how to protect the grid from these significant phenomena.

- INL met armor production deliverables for the U.S. Army, extending a long record of exemplary performance.

- INL successfully expanded its advanced vehicle testing activity supporting Office of Energy Efficiency and Renewable Energy (EERE) Vehicle Technologies Program, partnering with the DOE and dozens of industrial corporations. Expanding the use of light-duty electric vehicles is a top clean energy priority and provides market pull to expand deployment of nuclear energy.

- INL's Bioenergy Program completed 60 EERE Office of Biomass Programs (OBP) milestones including EERE's top priority 5 Joule milestones. INL successfully demonstrated, with third-party validation, achievement of OBP's biomass feedstock cost targets for corn stover harvest and storage.

- INL researchers created the Checkpoint Efficiency Tool (CET) and Aviation System Security Effectiveness Tool Suite (ASSET-S), integrated with the Adversary Threat Portfolio (ATP), to help the Transportation Security Administration (TSA) manage the complexity of their security system across the entire decision framework and evaluate numerous security alternatives in very short time frames. These evaluations will improve operational efficiency, reduce security wait times for passengers, and increase the overall effectiveness of the system. This capability is now being used in 20 of the nation's largest airports, with growing interest from the rest of the U.S., international airports, and ground transportation agencies.

- INL successfully demonstrated the ability to produce a glass ceramic waste form using INL-developed state-of-the-art Cold Crucible Induction Melter (CCIM). This first-of-a-kind result proves that the unique features (e.g., no exposed refractory, no in-melt electrodes, higher temperatures, higher 
throughput, and bottom drain) inherent in the design are well suited for producing advanced glass-ceramic High-Level Waste (HLW) forms.

\section{Capability Development}

INL continued to invest in development of capabilities to support future missions. Investments were made in new or upgraded physical plant, and more advanced experimental, analytical, safety, and business tools, instrumentation, and systems. Prominent among these INL capability enhancements were the following:

- Completed construction of the Irradiated Materials Characterization Laboratory (IMCL), providing research space for Haz Cat 2 quantities of radioactive material and a test bed for advanced characterization $\mathrm{R} \& \mathrm{D}$ techniques.

- Completed conversion of the Contaminated Equipment Storage Building to the Experimental Fuels Facility (EFF) to support large-scale fuel fabrication R\&D.

- Completed ATR Pressurized Water Loop 2A Center In-Pile Tube reactivation to support irradiation tests for industry.

- Added capabilities at Purdue, Pacific Northwest National Laboratory (PNNL), and Oak Ridge National Laboratory (ORNL) to the ATR NSUF program, bringing to 15 the number of unique capabilities accessible through NSUF besides ATR and HFEF.

- Installed a world class Spark Plasma Sintering facility in Center for Advanced Energy Studies (CAES) to enable research on high temperature nuclear fuels for space reactor and very high temperature reactor (VHTR) systems, secure and proliferation resistant radioisotope sources, irradiation resistant materials, high-density armor, and specialty irradiation target fabrication.

- Completed construction of the new Energy Systems Lab in October; commenced construction on the Research and Education Laboratory, which will collocate DOE programs with user facilities and serve as the gateway to the NSUF program.

- Developed and deployed the Mechanical Properties Microscope (MPM), a unique laser ultrasound instrument to measure mechanical properties of nuclear fuel. The MPM operates in a radiation hot cell environment via remote control to provide micron-level mechanical property information that is commensurate with microstructure heterogeneity essential to understanding the role of microstructure in determining mechanical properties of nuclear fuel.

- INL significantly expanded electric vehicle and stationary battery test system capability with procurement of over $\$ 5 \mathrm{M}$ of new equipment. This includes a new a Ling Dynamic Systems model V8-640 shaker system to test automotive energy storage devices, particularly Lithium-ion batteries, under normal or extreme driving conditions, and a new Bruker Hyperion 3000 FTIR microscope to study and analyze energy critical materials to improve production efficiency and product purity. 
- Completed other significant capability enhancements including:

- Assembly and change-out of the ATR Center Flux Trap Baffle (CFTB) with redesigned $\mathrm{N}-16$ tubing

- Seismic upgrades at ATR prompted by events at Fukushima

- At Materials and Fuels Complex (MFC), completed the modular Dial Room Replacement Facility, three new evaporative sewage lagoons and a primary lift station, and base phase construction of the Electrical Distribution Loop A

- Implemented Google Applications for Government

- Implemented Land Mobile Radio (LMR) replacement technology as a managed service.

In addition to developing new capabilities for its own use, INL contributed research products, expertise and resources to the development of new specific capabilities for other organizations. Examples include:

- The copyrighted MOOSE framework is currently being used nationally and internationally by a rapidly growing number of licensees.

- Defueling and cleanup lessons learned from TMI and DOE cleanup sites were shared with the Japanese to support Fukushima recovery efforts.

- RELAP licenses grew to an all-time high from 11 licenses executed in FY09 to more than 80 active licenses at the end of FY12.

- A commercialization strategy is being developed for Sophia, a powerful Supervisory Control and Data Acquisition (SCADA) system-fingerprinting tool that completed beta testing with industry partners.

- The Department of Transportation (DOT) tapped INL to update first responder training guidance for emergency response procedures for electric vehicle battery incidents.

- As in past years, INL sponsored many activities (internships, technical symposia, teacher training, fellowships, joint academic appointments, etc.) aimed at developing the technical capabilities of hundreds of students, researchers, and teachers who will contribute to the advancement or application of science and technology in the future.

\section{Leadership}

INL continues to seek leadership opportunities in technical, civic, and educational organizations, at the local, state, and federal levels, within DOE, and in domestic and international nuclear industry and academic circles. Examples include:

- Maintained technical integration leadership; INL is a recognized leader in fuel development, separations research and waste form development, systems analysis, risk and safety analysis, and demonstration of reactor and fuel cycle technologies. In FY12, based on INL performance in the radioisotope powersystem program, DOE expanded the INL technical integration role to radioisotope power systems. 
- INL executives John Grossenbacher, Dave Hill, and Phillip Finck Assumed leadership positions in Governor Otter's Leadership in Nuclear Energy (LINE) Commission.

- Developed the INL Laboratory Plan, which was recognized by the Under Secretary's Office for its clarity and close alignment with NE R\&D priorities and strategy.

- Provided national leadership in nuclear engineering and education; in FY 2012, INL administered Nuclear Energy University Program (NEUP) issued solicitations for $R \& D$ projects, more than $\$ 47 \mathrm{M}$ was awarded to 46 colleges and universities. Awards included 39 undergraduate fellowships, 31 fellowships, 26 grants for infrastructure and reactor upgrades, and 48 R\&D projects.

- Initiated collaboration among three Washington think tanks (The Center for Strategic and International Studies, $3{ }^{\text {rd }}$ Way, and the Bipartisan Policy Center) that were pursuing independent initiatives to explore the future of nuclear energy. INL worked with these groups to present the symposium on Ensuring a Safe and Secure Future for Nuclear Energy.

- Became the first DOE lab to move to "the Cloud" with an information system compliant with the Federal Information Security and Management Act (FISMA).

- Demonstrated visionary leadership in U.S. government initiatives for wireless innovation in spectrum sharing through national representation on strategic panels and committees, building collaborations that have advanced partnerships among government, industry, academia, and laboratories, and deploying innovative technical wireless communications solutions:

- Testimony on the need for national spectrum sharing testing to the U.S. Congress House Committee on Science, Space and Technology, Subcommittee on Technology and Innovation

- The first Spectrum Sharing Technical Workshop with industry, National Telecommunications Information Administration, Federal Communications Commission, DOE, Department of Defense (DoD), and INL to formulate a strategy for spectrum sharing research experimentation

- $\quad$ Receipt of national awards (e.g., R\&D 100, Far West Laboratory Consortium, Idaho Innovation Award) and patents for INL spectrum sharing technologies

- Technical lead reviewer for the U.S. Air Force Space Command in determining the interoperability of light-squared technology with the worldwide Global Positioning System.

- Advanced the Nuclear Hybrid Energy Systems (NHES) concepts in FY12, by providing key leadership at multiple DOE-Chinese Academy of Science (CAS) Protocol meetings led by Dr. Brinkman, SC-1, and his senior directors. Acting as honest brokers in Wyoming and with industry, INL increased the acceptance of NHES in the region. The State of Wyoming passed legislation to fund INL to study how hybrid energy systems can best be used to convert Wyoming's fossil and wind energy resources into higher value products; INL teamed with GE and NREL to pursue a Wyomingsponsored opportunity on advanced energy conversion technologies. 
- Became the strategic leader in nuclear and non-nuclear hybrid system concepts through the development and application of High Performance Dynamic Modeling and other computational tools, as well as system development and demonstration using Hardware-in-the-Loop. We have made significant advancements in computer modeling, simulation, and integration capability by developing process modeling and economic tools that are being used for technical, economical, and sustainability analysis of NHES. Evidence of INL impact in this area is seen in General Electric's recent request to have INL attend and represent them at an international conference in Munich, Germany on hybrid energy system modeling.

- Continued to provide significant leadership and technical expertise in support of the State of Idaho in developing its energy strategy. This includes providing key support to the State Energy Interim Committee to complete the 2012, 3-year, Idaho State Energy Plan and updating the Idaho Energy Primer. INL chairs the overall Idaho Strategic Energy Alliance (ISEA) effort, provides official state testimony and public meeting participation, as well as leads the carbon management for ISEA. INL has also been asked to provide an expert on the newly formed Transportation Task Force.

- As the lead DOE nuclear energy laboratory, participated in the Utah Governor's Energy Summit in Salt Lake City as part of a panel on nuclear energy. The Governor's Energy Office has also asked INL to prepare an assessment of the applicability of nuclear energy in Utah.

- Received Office of Acquisition and Project Management certification of the laboratory's Earned Value Management System.

\section{Performance Challenges in FY12}

INL performance in FY12 included shortcomings in nuclear operations and radiological controls, project execution, and institutional management. Specific weaknesses included:

- Serious plutonium incident, an unplanned exposure to high radiation, and a series of near-miss events that ultimately resulted in the Laboratory Director standing down operations at MFC.

- A number of visible projects (e.g., ATR Loop 2A, Restart of Transient Test Capability, and Materials Security and Consolidation Project) experienced issues that eroded DOE's confidence in INL's ability to manage projects.

- INL was slow to anticipate and adjust to funding reductions and cost impacts from operational stand-downs on research and infrastructure programs. INL also faced several internal management challenges, which were not addressed as effectively as they should have been. These included financial management, particularly in the area of indirect cost management, and workforce restructuring, areas which were greatly intertwined.

\section{Performance Evaluation and Measurement Plan (PEMP)}

Table ES-1 provides summary grades that we believe appropriately reflect INL performance against the Performance Evaluation Measurement Plan (PEMP) in FY12. Specifics on each measure are captured in the PEMP database and are not necessarily duplicated in this report. 
Table ES-1. Assessment of PEMP Performance by measure.

\begin{tabular}{|c|c|c|}
\hline Objective & Description & Grade \\
\hline 1.1 & R\&D Strategy Implementation and Impact & A \\
\hline 2.1 & Nuclear Energy Commitments & $\mathrm{B}+$ \\
\hline 2.2 & National and Homeland Security Commitments & $\mathrm{B}$ \\
\hline 2.3 & Other Mission Related Commitments & A \\
\hline 3.1 & $\begin{array}{l}\text { Progress Toward Developing World-Class Nuclear } \\
\text { Capabilities }\end{array}$ & A- \\
\hline 3.2 & $\begin{array}{l}\text { Progress Toward Establishing INL as a Major } \\
\text { Center for National Security Technology } \\
\text { Development and Demonstration }\end{array}$ & A- \\
\hline 3.3 & $\begin{array}{l}\text { Science and Technology Capabilities Supporting } \\
\text { the Principal Mission }\end{array}$ & A \\
\hline 3.4 & $\begin{array}{l}\text { Workforce Capabilities that Enable Principal } \\
\text { Missions }\end{array}$ & A \\
\hline 4.1 & $\begin{array}{l}\text { Engagement of the Nuclear Industry and Nuclear- } \\
\text { Interested Parties }\end{array}$ & A- \\
\hline 4.2 & $\begin{array}{l}\text { Enhance Regional, National and International } \\
\text { Partnerships }\end{array}$ & $\mathrm{A}+$ \\
\hline 4.3 & $\begin{array}{l}\text { Technology Transfer, Deployment and } \\
\text { Commercialization }\end{array}$ & $\mathrm{A}+$ \\
\hline 5.1 & Operations Performance in Support of Programs & B- \\
\hline 5.2 & $\begin{array}{l}\text { Validation of INL Operational Assurance } \\
\text { Activities }\end{array}$ & $\mathrm{B}+$ \\
\hline 5.3 & Project Management Improvements & $\mathrm{B}+$ \\
\hline 5.4 & Progress Towards Achieving Sustainability Goals & A- \\
\hline 5.5 & Safeguards and Security Threat Reductions & $\mathrm{A}+$ \\
\hline 6.1 & Quality Leadership in Management and Operations & A- \\
\hline
\end{tabular}




\section{CONTENTS}

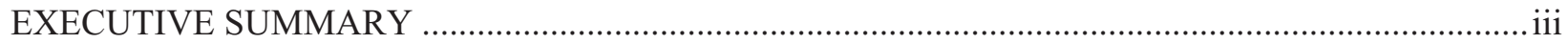

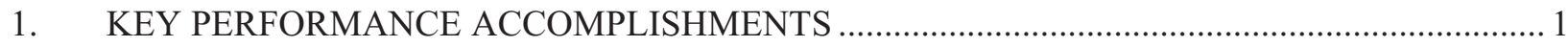

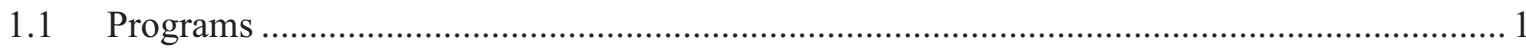

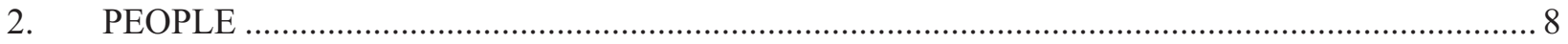

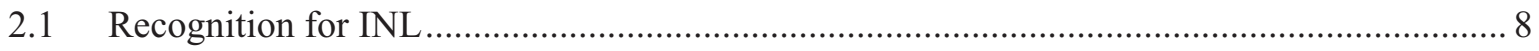

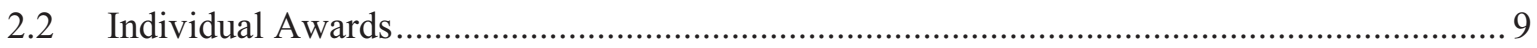

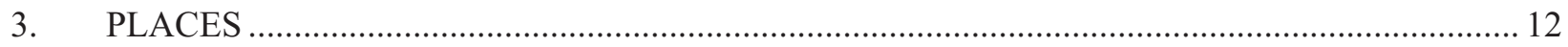

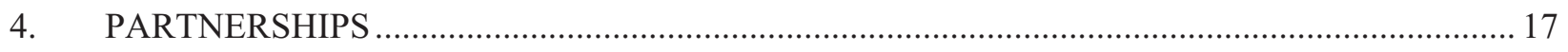

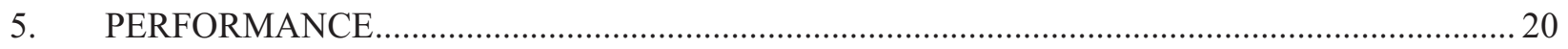

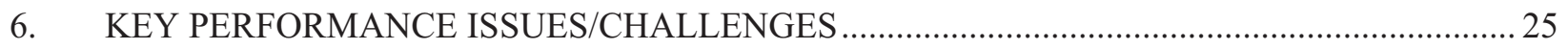

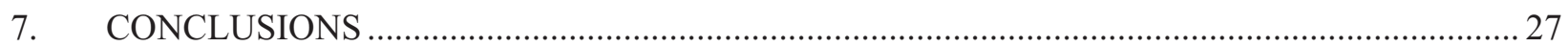

\section{FIGURES}

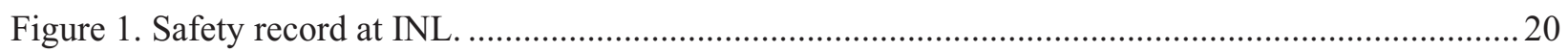

\section{TABLES}

Table ES-1. Assessment of PEMP Performance by measure ................................................................

Table 1. Examples of other significant achievements......................................................................... 5

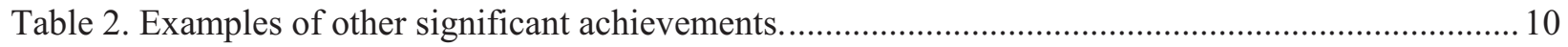

Table 3. Examples of other significant achievements..................................................................... 15

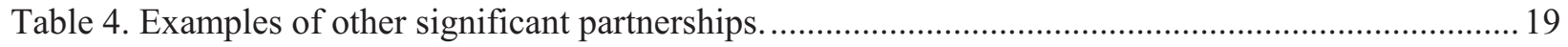

Table 5. Examples of other operating performance accomplishments. ...................................................24 


\title{
FY 2012 INL \\ Self Assessment Report
}

\section{KEY PERFORMANCE ACCOMPLISHMENTS}

\subsection{Programs}

\begin{abstract}
INL plays a key role in programs of national importance, shaping the nation's nuclear energy research agenda and building capabilities to meet users' needs through technical leadership and execution.
\end{abstract}

MOOSE Framework. MOOSE is the basis of the MBM (MOOSE-BISON-MARMOT) suite of codes being used to advance the understanding of nuclear fuel performance. BISON is a thermomechanical code used to explore fuel performance at engineering scale (continuum scale). With the proper constitutive models, MOOSE is applied to light water reactor (LWR) fuels as well as advanced fuels being considered for next generation of reactors. The MARMOT microstructure simulation tool investigates the changes in the fuel that occur at the microscale due to radiation damage to improve the predictive capability of the BISON code. MARMOT is based on phase-field formulation of the microstructure behavior. MBM is the standard for all fuel analysis within DOE, including CASL. Other applications being developed under MOOSE framework include RELAP-7 and the new GRISLY code for materials aging. It is also being used for non-nuclear problems such as environmental remediation of chemical spills, carbon sequestration, and oil shale recovery processes. The MOOSE framework is currently licensed for use by 25 domestic and foreign laboratories, universities, and companies; the user community continues to grow rapidly.

Mars Mission. On November 26, 2011, NASA's Mars Science Laboratory blasted off from Kennedy Space Center (KSC) with the Rover Curiosity heading for Mars in search of signs of life on the Martian surface. Curiosity, unlike the Spirit or Opportunity rovers that arrived in 2004, is powered by a nuclear heat-driven system provided by DOE. This power system was fueled, tested, and delivered to KSC by INL. This multi-mission radioisotope thermo-electric generator (MMRTG) is the first of this design and represents the culmination of almost a decade of effort by INL and many others (Oak Ridge National Laboratory, Los Alamos National Laboratory, Teledyne Energy Systems, and Pratt \& Whitney Rocketdyne). The power system will provide over 100 watts of power that will enable the planned 24month mission of Curiosity to Mars. The system was fueled and tested by INL in 2008 and stored at INL until needed at KSC for the mission in 2011. INL provided ground support at KSC from mid-summer through launch in late November. The landing on Mars on August 5, 2012 at 11:30 PM MDT, watched avidly by many associated with the work in Idaho, resulted in images of the Martian surface being sent back almost immediately. Curiosity's continuing scientific mission through 2014 should be of great interest to the entire laboratory and serve as tremendous "warm-up" to the arrival of the laboratory's other earlier effort involving the power system on NASA's Pluto New Horizon space probe that is due for an encounter with the planet Pluto in July 2015, launched in January 2006.

Light Water Reactor Sustainability (LWRS). INL leads the LWRS Technical Integration Office (TIO) and three of the four technical pathways (Instrumentation, Information, and Control, Risk Informed Safety Margin Characterization, and Advanced Light Water Reactor Fuels). In January 2012, the LWRS TIO issued the LWRS Integrated Program Plan describing the LWRS program objectives, technical plans, and interfaces with industry partners and other DOE programs. It also includes an overview of each of the LWRS Pathways, and a description of major deliverables to be completed by each pathway, with an emphasis on deliverables between now and 2016. 
- The Information, Instrumentation and Control (II\&C) Pathway is leading a series of pilot projects at commercial reactor sites and in the INL Human Systems Simulation Laboratory to demonstrate digital technologies that will enable the modernization of legacy II\&C systems and provide an operating model that will significantly enhance nuclear safety, worker productivity, and overall plant performance. We were notified in July that one of the technologies demonstrated this FY in an INL-led pilot project will be implemented in nine Exelon plants.

- The Risk Informed Safety Margin Characterization (RISMC) Pathway is combining probabilistic and mechanistic approaches to provide a decision-making tool for nuclear power plant owners. In FY12, INL demonstrated the RISMC methodology using the INL ATR. As part of the demonstration, we describe how both the thermal-hydraulics and probabilistic safety calculations are integrated and used to quantify margin management strategies. Completing the ATR case study has pointed to several additional areas of promising R\&D related to risk-informed margin management.

Wireless Communications. INL's strategy to build nationally leading wireless communications research, development, demonstration, and deployment capabilities was validated during FY12 through several significant technical leadership innovations and public events. In FY12, INL:

- Received international recognition for development of innovative spectrum sharing technology, WSComm, through the announcement of a 2012 R\&D 100 Award

- Provided impactful testimony to the U.S. Congress House Committee on Science, Space and Technology, Subcommittee on Technology and Innovation in support of the need for a national wireless test bed to advance the national Wireless Innovation Initiative

- Participated as a member of the Office of Science and Technology Policy Wireless Spectrum Sharing R\&D Task Force

- Received external validation of INL's unique capability to serve as a national wireless test bed for spectrum sharing technology test and evaluation.

LEU Fuel Conversion. Mexico's ININ research reactor was converted from highly enriched uranium (HEU) to low-enriched uranium (LEU) and all U.S. origin HEU removed. INL's Eric Woolstenhulme was recognized for his support in orchestrating the delivery of LEU from France and delivery of equipment. The conversion was a highly visible priority for the National Security Council leading up to the Nuclear Security Summit in South Korea at which President Obama's address cited the ININ reactor conversion as an example of excellent regional partnership.

Protecting the Grid. INL conducted a highly successful, full-scale test using our electric grid to determine the effects of Geomagnetic-Induced Currents (such as those generated by a solar storm) coupled onto the grid. This was a follow-up test to a first-ever transformer test performed last year. Following last year's test, INL provided a brief of the electromagnetic pulse (EMP) testing to the Congressional EMP Caucus to assist in defining the need for grid protection in the event of a natural or manmade EMP. Several entities, including the North American Electric Reliability Council Geomagnetic Disturbance Task Force, Institute of Electrical and Electronics Engineers (IEEE), and the office of Senator Lisa Murkowski (R-Alaska), requested follow-up briefs. The follow-up test included the introduction of multiple mitigation strategies under different load and current conditions, and the data collected will greatly advance the nation's understanding of how to protect the grid from these significant phenomena.

National Nuclear Security Administration (NNSA) Cybersecurity. INL was selected to support the NNSA Office of Defense Nuclear Security (NA-70) in examining the cyber-related vulnerabilities of NNSA facilities where Category 1 nuclear and radiological sources are present. The work leverages the lab's unique skills and facilities to advance program with cyber and physical security, and nuclear facility operations initiatives. 
Vehicle Technologies Program. DOE's recognition of INL expertise in advanced vehicle and energy storage technology and affirmation as "the place to go" for energy storage device testing and performance validation is demonstrated by our participation in an "invitation-only" DOE Electric Vehicle (EV) Everywhere Planning Meeting with Secretary of Energy Steven Chu and EERE-Assistant Secretary David Danielson.

Nuclear Hybrid Energy Systems (NHES). Advancing the NHES concepts in FY12, INL provided key leadership at multiple DOE-Chinese Academy of Science (CAS) Protocol meetings led by Dr. Brinkman, SC-1, and his senior directors. Acting as honest brokers in Wyoming and with industry, INL increased the acceptance of NHES in the region. The State of Wyoming passed legislation to fund INL to study how hybrid energy systems can best be used to convert Wyoming's fossil and wind energy resources into higher value products. INL also teamed with GE and National Renewable Energy Laboratory (NREL) to pursue a Wyoming sponsored opportunity on advanced energy conversion technologies.

Transportation Security. INL researchers created the Checkpoint Efficiency Tool (CET) and Aviation System Security Effectiveness Tool Suite (ASSET-S), integrated with the Adversary Threat Portfolio (ATP), to help the Transportation Security Administration (TSA) manage the complexity of their security system across the entire decision framework and evaluate numerous security alternatives in very short time frames. These evaluations should improve operational efficiency, reduce security wait times for passengers, and increase the overall effectiveness of the system. It allows TSA to better evaluate its readiness to defeat future threats. This capability is now being used in 20 of the nation's largest airports, with growing interest from the rest of the U.S., international airports, and ground transportation agencies.

Mechanical Properties Microscope (MPM). INL developed and deployed a unique laser ultrasound instrument to measure mechanical properties of nuclear fuel. The MPM, developed under the Fuel Cycle Research and Development (FCRD) program, is designed to operate in a radiation hot cell environment via remote control. The MPM provides micron-level mechanical property information that is commensurate with microstructure heterogeneity essential to understanding the role of microstructure in determining mechanical properties of nuclear fuel. The MPM will help INL develop advanced nuclear fuels with improved reactor performance and safety margins.

Glass Ceramic Waste Form. INL successfully demonstrated the ability to produce a glass ceramic waste form using our state-of-the-art Cold Crucible Induction Melter (CCIM) for the FCRD program. This first-of-a-kind result proves that the unique features (e.g., no exposed refractory, no in-melt electrodes, higher temperatures, higher throughput, and bottom drain) inherent in the design are well suited for producing advanced glass-ceramic High Level Waste (HLW) forms. Efficient and effective immobilization of HLW is critical to the regulatory and economic viability of fuel recycling.

INL Laboratory Plan. The INL Laboratory Plan was submitted to DOE Headquarters (HQ) in June 2012 and briefed to the Under Secretary for Energy by John Grossenbacher. Feedback from the Under Secretary's staff indicated the INL and its plan were “...intimately linked with NE's 2010 roadmap for the future and NE's strategy for delivering on the objectives of the road map...The INL plan is strengthened by that integration and, ultimately, provides a very clear, realistic, and exciting picture of the INL of the future. More specifically, the INL plan addresses the needs to (1) sustain the existing energy infrastructure until we have better infrastructure, (2) determine what the future energy system looks like and develop paths to reach it, and (3) provide for systems analyses of the energy system, understand resources, and mitigate impacts."

Space and Defense Power Systems TIO. DOE designated INL's Stephen Johnson to lead the newly established TIO for national lab work for the Office of Space and Defense Power Systems. Johnson will coordinate and integrate efforts among DOE and the laboratories, ensuring adequacy of planning and technology advancement for the space and defense infrastructure capabilities program. The TIO will also 
coordinate with University of Dayton Research Institution, Orbital Sciences Corporation, and other organizations.

RELAP Licenses. RELAP licensing grew to an all-time high, transferring analytical capabilities developed by INL over the years. INL executed 11 RELAP licenses in FY09; at the end of FY12, there are 80 active licenses on various versions of RELAP with more than 50 organizations, including more than two dozen foreign entities, employing its capabilities.

TRISO Fuel Development. First-of-a-kind analyses of the Advanced Gas Reactor (AGR-1) irradiation experiments performed in the ATR achieved a level of detail never reached before. Researchers were able to model explicitly each tristructural-isotropic (TRISO) fuel particle (less than 1 $\mathrm{mm}$ in diameter) present in the compacts being tested. The discrepancies between the calculated and measured plutonium atom densities created during the irradiation were greatly reduced compared to those obtained during prior analyses.

ATR National Scientific User Facility (NSUF) Projects. The ATR NSUF awarded 12 new projects during the year. Some of these were/will be performed in the ATR and other INL laboratories, and some were/will be performed in ATR NSUF partner facilities at other universities and national laboratories. The first joint ATR NSUF/NEUP proposal was awarded.

ATR NSUF Reports to EPRI. The ATR NSUF submitted two reports to EPRI to report completion of the Phase I and II Cooperative Research and Development Agreements (CRADAs) on the pilot project for testing of X-750 and XM-19. Phase I was baseline characterization and specimen machining of the material; results compared favorably with GE Global Research work, which is the standard for this type of testing. Phase II was test train design and thermal and neutronic analysis in preparation for the Phase III work, which will start in 2013, to irradiate the material and perform the post irradiation examination on the material.

Fukushima Support. The Japan/U.S. Department of Energy Workshop on Fukushima Daiichi Nuclear Power Plant Cleanup was organized by DOE-NE and DOE-EM to assess how lessons learned in the defueling and cleanup of Three Mile Island and environmental cleanup at Hanford, Savannah River, and INL might be applied in Japan. INL's Steve Herring was the NE organizer of the meeting, which was attended by 50 Japanese officials from government agencies and TEPCO along with DOE national lab researchers and U.S. Embassy staff. INL experts also advised Japanese nuclear industry representatives on $R \& D$ in the area of instrumentation and control (I\&C) technologies to better monitor plant conditions during severe accidents.

Industrial Control System Mission Support Center. The Secretary of Energy, Deputy Secretary of Energy, Assistant Secretary for Electricity Delivery and Energy Reliability, and Director of Intelligence and Counterintelligence were briefed in support of two significant national security policy decisions. INL technical leads for control systems security, cyber security, and intelligence threat analysis illustrated the impact of establishing a national threat analysis and response capability. The Director of National Intelligence has recognized INL as a national asset in meeting these threats.

Center for Advanced Modeling and Simulation (CAMS). Successfully demonstrated advanced visualization capabilities using CAVE technology. Examples include:

- Combined 3-D modeling and physics simulation data to render a true-to-scale model of ATR

- Rendered microscopy data (SEM, FIB, TEM, LEAP) in the CAVE to support the analysis and characterization of advanced materials for reactor and fuels programs

- Generated simulations of grid transmission routes by superimposing 3-D graphics on LIDAR data to depict the environmental impacts of transmission corridors

- Developed 3-D virtual environments from High Performance Computing (HPC) data including INL's MOOSE. 
MANTRA. MANTRA is an integral reactor physics experiment funded by DOE Office of New Production Reactor (NP), ATR-NSUF and ATLAS-NSUF to provide data on neutron cross sections for advanced fuel cycles. The first batch of MANTRA samples was fabricated in MFC's Analytical Lab and loaded in the ATR for an irradiation cycle beginning in February. A boron filter wrapped around the samples helped to narrow the focus to a fast neutron energy range not usually investigated in ATR. The MANTRA experiments seek a more precise understanding of isotope formation in various types of fuel.

Nonproliferation Center of Excellence. Substantial progress was made toward establishing INL as a Nonproliferation Center of Excellence with rollout expected early in FY13. In FY12, INL issued and began implementation of two plans related to establishment of the Nonproliferation Technologies Evaluation Center (NTEC). In preparation for the rollout of NTEC, INL finalized a list of materials to be retained, received approval for a safety basis upgrade, and restored ZPPR operational status.

Table 1. Examples of other significant achievements.

\section{Draft "Used Nuclear Fuel Storage and Transportation RD\&D Plan," was sent to DOE-HQ. DOE-NE will determine the next steps for the RD\&D plan. The primary objective of the plan is to provide confidence that Used Nuclear Fuel (UNF) can be safely stored and transported until facilities are available for final disposition.}

IMPACTS. INL initiated a new annual publication that highlights INL mission accomplishments. Distribution was made to university engineering departments nationwide, media outlets, national lab directors, Idaho university presidents, LINE commission members, Governor Otter and Idaho's delegation.

\section{DOE-EPA Interagency Energy-Water}

Program. INL participated in the first coordination and planning meeting to share DOE energy-water related research with Environmental Protection Agency (EPA). INL leadership at this meeting will help DOE support joint future water research.

Battlefield Radiation Sensor. Prototyped a radiation sensor module to integrate with a recently developed chem-bio testing system manufactured by Universal Energy Systems (UES Inc.) for the U.S. Army. The system tests for water-borne contaminants onsite in a matter of minutes as opposed to existing systems that take days to return results.
Two-Stage Anaerobic Digesters (AD). Center for Advanced Energy Studies (CAES) completed a 3year study that demonstrated the potential of twostage systems to improve biogas production and generate high-value byproducts compared to enclosed bioreactors. Potential of the AD to meet the United States Department of Agriculture's (USDA) goal of a $25 \%$ greenhouse gas (GHG) reduction by 2020 is being assessed.

Nuclear Hybrid Energy Systems (NHES) deployment strategy. INL provided a strategy for developing and deploying NHES to DOE-ID. The strategy outlines a 5-year approach toward the delivery of a NHES Demonstration Plan and includes development of computational tools, intelligent monitoring, and controls, and user interface systems.

Nitride/Silicide Fuels. A CAES team from INL, Boise State University, UW-Madison, and Westinghouse is developing corrosion resistant, high uranium density, LWR nitride and silicide fuels. A novel route to the synthesis of uranium silicide was demonstrated using cerium as a surrogate.

INL Data Management Recognized at the $\mathbf{2 0 1 2}$ FedFleet Conference. INL leadership in the automation of transportation data management was recognized at 2012 FedFleet, the federal conference that focuses on motor vehicle fleet management. 


\section{International Atomic Energy Agency}

(IAEA) support. INL hosts safeguards training programs for U.S. candidates for IAEA inspector positions, supporting the U.S. government goal to improve their success rate. IAEA has designated INL as the preferred provider of Plutonium Diversion Detection Training instruction. INL also provides pyro-processing training for IAEA inspectors.

\section{International Wood Composites}

Symposium. INL presented "Expanding Our Thinking of Woody Feedstock Supply Systems" at the symposium. The presentation addressed the expertise of INL's Bioenergy Program, which is recognized by the broader bio-energy community and industry.

\section{Battery Life Expertise. Dr. Jon} Christophersen presented an invited keynote address on "Developing Modeling Capability to Predict Battery Life" at the 2012 Prognostics and System Health Management Conference in Beijing. The conference draws the global community of Prognostics Health Management (PHM) experts in research and applications as diverse as aeronautics, defense, power and electronics systems, process industries, computers and telecommunications, material systems, industrial automation, healthcare, and medical technology.

Fuel Cycle Technologies Program. The Fuel Cycle Technologies Program annual meeting was held at ANL on November 810,2011 . The meeting was organized by INL and attended by approximately 150 researchers and managers from across the DOE complex. The DOE program manager described the meeting as "The best meeting I've attended during the 12 years I've been involved with this program," due to the meeting's organization and the high quality of the technical information that was presented.
Targeted Energy Management Toolset. A CAES collaboration on energy efficiency in commercial buildings developed an Android-based state awareness system that interrogates building energy management system data and identifies building state anomalies and human comfort data to optimize energy efficiency opportunities without sacrificing human comfort.

Power Magazine. Ken Thomas authored an article that appeared in Power Magazine. The article entitled: "Crossing the Digital Divide" relates the challenges of modernizing instrumentation and control technologies in today's nuclear power plants to sustain these plants for long-term operation.

\section{Changes in Mechanical Properties. Small} specimen test techniques were developed for evaluating radiation-induced changes in mechanical properties. This work supports DOENE priorities including LWRS, NGNP, and training for a new generation of radiation materials scientists. The new capabilities include:

- Enclosed and HEPA-vented shear punch and mini tensile testers

- Modified drop tower to perform tests on small Charpy samples

- A micro density measurement device to measure the post-irradiation swelling of $3 \mathrm{~mm}$ discs.

Nuclear Regulatory Commission. Dr. Kathryn McCarthy, Director of the LWRS Program TIO, presented an update on the LWRS Program at a meeting to discuss and coordinate on-going and planned long-term operability research programs being conducted by the EPRI, DOE-NE's LWRS Program, and NRC's Office of Nuclear Regulatory Research. These Long-Term Operations research programs are specifically looking at developing the technical information needed to make regulatory and business decisions regarding possible subsequent license renewal applications for the 60 80 year extended operating period. 


\begin{tabular}{l} 
Grid Transmission Site Suitability \\
Decision Support Technology. A prototype \\
GIS decision support tool that performs \\
least-cost path analyses to identify \\
feasible/optimal transmission corridors by \\
integrating geospatial data with socio- \\
political constraint survey data, and renders a \\
visualization of the results was developed \\
through CAES. \\
\hline Defense Advanced Research Projects \\
Agency (DARPA) Deployable Reactor \\
Project. INL delivered an assessment on the \\
viability of deployable reactors to DARPA. \\
The assessment evaluated various small scale \\
reactor concepts from the perspective of \\
prototype development and mitigation of \\
hostile threats throughout transportation, \\
deployment, operation, redeployment and \\
retirement, DARPA is considering \\
demonstrating a small ( 10 MWe) reactor \\
within 6 years.
\end{tabular}

\section{Syngas Conversion to Jet Fuel Range}

Hydrocarbons. INL researchers verified their discovery of a new catalytic process to convert synthesis gas $\left(\mathrm{CO}\right.$ and $\left.\mathrm{H}_{2}\right)$ into jet fuel range hydrocarbons. This new one step process does not require subsequent separation of products to obtain the desired jet fuel or diesel product. A private firm has agreed to support further development of this process and to commercialize it.

DHS Recovery Transformer Project. In a test of emergency response to major outages of transmission level transformers, INL participated in an exercise in, which three single-phase 345/138 KV transformers were transported from the ABB factory in St. Louis to CenterPoint Energy in Houston. The project team included Department of Homeland Security (DHS), Electric Power Research Institute (EPRI), CenterPoint Energy, and ABB. 


\section{PEOPLE}

INL is being acknowledged for its leadership and technical contributions. The laboratory continues to invest in employees and workforce development efforts to develop needed skills in science, technology and leadership.

Nuclear Energy University Programs (NEUP). INL competed, awarded, and is administering more than $\$ 47 \mathrm{M}$ in 2012 NEUP awards to 46 colleges and universities. Awards included 39 undergraduate fellowships, 31 fellowships, 26 grants for infrastructure and reactor upgrades, and 48 R\&D projects. Since 2009, NEUP has awarded \$219M to 81 schools in 34 states and the District of Columbia.

Energy Systems Technology and Education Center (ESTEC). The first class of students entered the ESTEC nuclear operations technician program at Idaho State University. Five of the new enrollees in the 2-year program interned at ATR and MFC this year. ESTEC's nuclear operations technician is funded in part by INL and the NRC. ESTEC offers career-training programs spanning established and emerging energy sectors.

Workforce Development Funding. Proposals were submitted to the Department of Labor with support letters from Idaho Department of Education, State Board of Education, and several business partners. Idaho submitted a work plan in November for the $\$ 2.7 \mathrm{M}$ grant. INL is working with the college consortia to keep industry involved in the development of the programs, which are focused on remediation efforts for students entering 2-year programs with inadequate math skills.

Internship Programs Achieve Best-in-Class Again. INL was recognized again in FY12 as a top internship program by Vault Guide, the recognized authority among independent internship program evaluators. INL hosted more than 200 interns in FY12, attracting more students from higher-tiered universities and with higher grade point averages (3.6 on average). INL has experienced more than a three-fold increase in applicants to the INL program since 2008 with graduate and Ph.D. students now being the majority of applicants vs. mainly undergraduate and high school students in years past.

i-STEM. INL leadership was showcased at the National Science Teacher Association STEM Forum and the STEMx Solutions Summit. Agrium and Simplot joined the partnership this year and provided financial sponsorship. INL, i-STEM partners, and the Idaho State Board of Education held the first ever state STEM summit in May. Over 200 participants engaged in working sessions to help develop the goals and measures for a statewide STEM education roadmap. Governor Butch Otter issued a proclamation declaring June 2012 "STEM Education Month."

\subsection{Recognition for INL}

External Release Summary. More than 3100 items were reviewed and approved for release through the Scientific and Technical Information Management System (STIMS) during FY12. These include conference papers and presentations, technical reports, journal abstracts and articles, and various other products to be shared outside of INL. INL researchers published in journals in technical fields ranging from nuclear technology to space science to virology.

Canadian Unconventional Resources Conference. INL staff gave an invited presentation on integration of nuclear power with unconventional oilfield operations at the conference sponsored by the Society of Petroleum Engineering and the Canadian Society for Unconventional Resources.

Commisariat Energie Atomique (CEA). Dr. Jon Carmack attended this year's Frederick and Juliet Otto-Hahn (FJOH) school at the invitation of the CEA organizers, and provided 2 days of lectures on the science and performance of nuclear fuels and materials. This is international recognition for Dr. Carmack and demonstrates international leadership in nuclear fuel development by INL. 
Information Management Leadership. INL's leadership in cyber security and records management was recognized at the 2012 DOE Information Management Conference. INL's chief security officer, Jeff Pack, and laboratory records officer, Lorrie Robb, presented on topics including "Implementing the Risk Management Approach," and "Taking Records Management Inventories into the $21^{\text {st }}$ Century. " INL representatives also facilitated workshops and appeared on multiple panel discussions.

Sustainability. INL received the first Department of Energy Management Award to recognize the exemplary Sustainability Program team for outstanding contributions to energy, fuel, and vehicle fleet management and associated cost savings at INL facilities.

Chinese Academy of Sciences. INL and American Nuclear Society (ANS) Fellow and Director of VHTR Technology Development, Dr. David Petti, was an invited expert on an international panel convening in Shanghai, China. The panel's purpose was to review the thorium molten salt loop technical design and the $2 \mathrm{MW}$ pebble bed fluoride high-temperature reactor conceptual design and provide an independent, in-depth assessment of the state of readiness of the design and associated technology development.

Dr. Rangam Subramanian, INL's Chief Wireless and Technology Strategist testified as a witness at a hearing of the Subcommittee on Technology and Innovation of the House Science, Space and Technology Committee. The hearing focused on "Avoiding the Spectrum Crunch: Growing the Wireless Economy through Innovation." Dr. Subramanian, along with witnesses representing National Institute of Standards and Technology (NIST) and industry testified in support of establishing a full-scale national wireless test bed.

Dr. Kathryn McCarthy was asked to serve on a National Academy of Sciences committee to assess the prospects for inertial confinement fusion energy systems. Dr. McCarthy was also selected to receive the Partnership for Science \& Technology 2011 Nuclear Energy Advocate of the Year Award. The Nuclear Energy Advocate of the Year Award is presented to individuals who were central to noteworthy achievements in nuclear energy.

\subsection{Individual Awards}

Secretary Chu presented INL staff members the prestigious Secretary's Achievement Honor Award for their role in supporting DOE's response to the Fukushima disaster. The honor awards represent the highest internal non-monetary recognition given by DOE for providing exceptional service to the Department and the American people.

INL scientist Derek Gaston was awarded the Presidential Early Career Awards for Scientists and Engineers by President Obama. As leader of the Computational Frameworks Group in INL's Fuel Modeling and Simulation Department, Gaston has led the development of the MOOSE software framework being used by laboratories and research institutions around the globe to create cutting-edge simulation codes.

Dr. Hussein Moradi and Dr. Carl Kutsche brought home a 2012 R\&D 100 Award for their innovative wireless technology platform, Wireless Spectrum Communications (WSComm). WSComm is based on a patent-pending spectrum-agile algorithm. The INL inventors developed the technology in collaboration with Utah State University researchers. INL has received 47 R\&D 100 Awards since 1986.

Eric Howden received the 2011 Secretarial Honor Award. This award is the highest DOE nonmonetary recognition that DOE employees and contractors can receive and recognizes the exceptional service. Mr. Howden, an INL assignee to NNSA's Office of Global Threat Reduction, provides leadership for the removal of special nuclear material from the former Soviet Union plutonium production facility (BN-350). 
Nancy Bergmann was honored by the Southern Idaho Economic Development Organization by creation of The Nancy Bergmann/INL Math \& Science Scholarship, managed by the College of Southern Idaho Foundation. The scholarship was established as Nancy approached retirement in recognition of the many contributions she and INL have made in support of economic development efforts in southern Idaho.

INL's 16th Annual Honors Reception. The Honors Reception highlighted the importance of new technology and celebrated dozens of INL inventors who developed and patented new technology that can be or already have been licensed for commercialization. The 2011 award recipients of the Laboratory Director's awards included:

- Dr. Richard Wright - Exceptional Scientific Achievement

- Dr. Carl Stoots - Exceptional Engineering Achievement

- Dr. Peter Zalupski - Early Career Exceptional Achievement

- Dr. Gus Caffrey - Individual Lifetime Achievement in Science and Technology

- Todd Morris - Technician of the Year.

Federal Laboratory Consortium (FLC) Awards. INL inventors and technology transfer professionals won three FLC Far West Region awards for 2012.

- Lisa Nate and licensee Lindsey Manufacturing were recognized for an Outstanding Partnership for Work to Protect High-Voltage Transmission Lines from Sabotage using INL's Transmission Line Security Monitor

- INL's Dr. Hussein Moradi, Dr. Carl Kutsche and their wireless research team earned honors as an Outstanding Technology Development for Wireless Spectrum Communications (WSComm)

- Jason Stolworthy, Deputy Director of Technology Deployment, won recognition as the Far West Technology Transfer Professional of the Year.

Table 2. Examples of other significant achievements.

\section{Dr. Jon Christophersen's Impedance Measurement Box (IMB) battery diagnostic tool technology was a runner-up in the Energy category of this year's Wall Street Journal Technology Innovation Awards.}

Brent Stacey was named one of the Top 100 CIOs by Computerworld Magazine.

Karl Black received an award for successful collaboration in developing a Risk Management Methodology and the Dynamic Attack Tree Tool (DATT) at the 2012 DOE Information Management Conference.

\section{Dr. Eric Steffler and Wayne Austad are} supporting the Director of National Intelligence (DNI) Scientific and Technical Intelligence Committee (STIC), advising DNI's S\&T senior intelligence officer on threats.
Dr. David Miller was named to serve as a peer reviewer for the National Research Council report entitled "The Role of the Chemical Sciences in Finding Alternatives to Critical Resources."

Rita Wells was appointed to the DHS Homeland Security Advisory Council's (HSAC) Task Force for Cyber Skills (TFCS).

Robert Podgorney chairs the U.S. delegation Chair to the International Partnership for Geothermal Technology. Rob is responsible for developing protocols associated with the U.S. role in widespread adoption of Enhanced Geothermal Systems (EGS).

INL received a Special Achievements in Geographical Information System (GIS) Award from GIS software provider, ESRI. INL received the award for work incorporating geographic information into our Advanced Vehicle Testing Activity (AVTA) for the DOE's Vehicle Technologies Program. 
Nuclear Energy Agency of Mongolia. Steve Herring and Bonnie Hong earned kudos from DOE-NE for their participation in the US-Mongolia Second Expert Level Meeting in Ulaanbaatar.

David Everett and Maxine Rubick, Region 6 RAP Team members, were recognized by NNSA for their deployment to Japan to help recovery from the Fukushima event. INL was presented a plaque in recognition of outstanding overall support.
International Congress on Advanced Power Plants (ICAPP). Associate Laboratory Director Dr. Steven Aumeier was a plenary speaker at ICAPP presenting on nuclear hybrid energy systems.

Ken Rohde and Rita Wells of INL and Neil Hershfield of the DHS accepted the 2011 U.S. National Cybersecurity Innovation Award from the SANS Institute on behalf of INL and DHS for building cyber security skills needed to defend the power grid and other control systems. 


\section{PLACES}

INL continued investments in new and upgraded infrastructure and state of the art instrumentation and tools to develop, demonstrate and deploy research capabilities expected of a world class laboratory.

ATR Life Extension Program. The ATR Life Extension Program (LEP) met key objectives, improving the ATR's ability to provide critical customer irradiations in the future. Technical upgrades and replacement of aging systems were made to improve plant reliability and sustainability and better support irradiation programs.

- Initiated the conversion of the ATR to $100 \%$ commercial power design in anticipation of procuring safety-related uninterruptable power supply and batteries during the first quarter of FY013.

- Continued development on the new ATR core modeling capability with completion of several ATR critical facility irradiation experiments that support verification and validation of the new physics methods.

- Received 20 nitrogen-16 detectors for the ATR nuclear instrumentation system upgrade and initiated engineering design for nuclear instrumentation subsystem electronics.

- Continued to enhance ATR production control processes by standing up the ATR Outage Control Center and developing a Shutdown Risk Management process. Both of these actions support and enhance defense in depth by ensuring a focus on maintaining safety functions during reactor shutdown periods.

- Satisfactorily tested the newly designed N-16 Beta Detectors to support Nuclear Instrumentation Replacement.

Fukushima-Related Seismic Modifications. Modifications were undertaken (some completed) at ATR, including:

- An upgrade to the seismic supports for ATR heat exchangers and primary coolant pumps

- Installation of the auxiliary canal fill system in support of defense in depth beyond design basis events

- Design and procurement of additional portable emergency response equipment including a portable diesel backup for the ATR emergency coolant pump in the event a station blackout occurs.

ATR NSUF Irradiation Assisted Stress Corrosion Cracking (IASCC). INL continued efforts on the IASCC Project during FY2012 and demonstrated substantial progress in the design, procurement, assembly, testing, and installation of two IASCC test rigs in the Fuel and Applied Science Building (FASB) at MFC. Additional accomplishments included completion of the following:

- Fabrication, assembly, and testing of the IASCC Hot Cells at the vendor's facility

- Disassembly and shipment of the hot cells from the vendor's facility to the INL

- Reassembly of the hot cells in Vault 101 of the FASB facility

- $\quad$ Rad Shine Test and re-confirmed operational tests of the hot cells

- Utility modifications and upgrades to the FASB facility

- Design, fabrication, procurement, and mock-up testing of all IASCC test rig equipment. 
Pressurized Water Loop 2A. Upon recognizing management, performance and funding issues associated with the ATR Loop 2A, Battelle Energy Alliance (BEA) conducted a focused triage effort to characterize the issues and drive remediation of the execution of the project. Installation, testing, operations turnover, and Contractor/DOE readiness assessments were completed within the performance baseline schedule and the revised budget.

Irradiated Materials Characterization Laboratory (IMCL). Construction of the IMCL was completed. IMCL is a Hazard Category 2 nuclear facility designed to allow INL to prototype, develop, and test advanced post-irradiation examination instruments and methods.

Advanced Postirradiation Examination. A preliminary baseline through CD-4 was established and one Level 2 and three Level 3 milestones were completed on or ahead of schedule. An accelerated schedule to achieve CD-1, with attendant risks, was submitted to aid in setting FY14 budgets. Additional accomplishments include the following:

- Submitted a plan for performing the alternative analysis for advanced PIE capabilities

- Submitted a draft acquisition strategy

- Submitted a NEPA compliance strategy

- Completed a draft safety design strategy on July 24, 2012.

Transient Test Capability. INL remobilized the Transient Test Capability capital asset project in February 2012 and demonstrated substantial progress in the re-establishment of the domestic capability for transient nuclear fuels testing including the following:

- Required programmatic documents including the Acquisition Strategy, the Preliminary Project Execution Plan with the Critical Decision Tailoring Strategy, the Safety Design Strategy and the Major Modification Determination were delivered ahead of schedule

- Conceptual design continued and supported the Analysis of Alternatives effort, which culminated with the identification of the INL Transient Reactor Test (TREAT) facility as the recommended alternative to resume domestic transient testing of nuclear fuels

- The Nuclear Safety Integration Guide for revising the TREAT facility Safety Analysis Report to comply with current DOE Safe Harbor requirements was completed.

MFC Sewage Lagoons. Completed construction of the new wastewater system including three new high-density polyethylene (HDPE) lined lagoons, a new perimeter access road, chain link fencing surrounding the lagoons, and the Idaho Department of Environmental Quality (DEQ) required seepage rate testing. In addition, the primary lift station was refurbished, specifically the removal of the old lift station pumps and other miscellaneous mechanical and electrical components, demolition of the pumphouse building, installation of a new force main utilizing pipe bursting technology, rehabilitation of the concrete wet well, which includes pressure washing and the application of interior epoxy coatings, and installation of new pumps, controls, and other miscellaneous mechanical and electrical equipment.

MFC Dial Room. Completed construction of the new MFC Dial Room, which replaces the existing failing telecommunication Private Branch exchange (PBX) switches at the MFC/PBF/CFA/RWMC Dial Rooms and provides new data network infrastructure at the MFC Dial Room.

Remote Handled Low Level Waste (RHLLW) Disposal Project. An Environmental Assessment (EA) was completed and DOE-ID issued a FONSI following public review of the EA in December 2011. A Facility Performance Assessment was completed and submitted to Low Level Waste Federal Review Group (LFRG) for review and concurrence. Received a commendation from LFRG for a thorough and complete assessment and the LFRG issued Preliminary Disposal Authorization Statement for project in April 2012. All procurement activities necessary to award a $\$ 35 \mathrm{M}$ design-build subcontract for construction of the RHLLW Disposal Facility were completed. A combined Critical Decision-2/3 
approval request to proceed with project execution was submitted to DOE for review and approval in May 2012. The project successfully completed all external reviews necessary to obtain approval of these critical decisions, which was received in August 2012.

Material Security and Consolidation Project. INL completed the transfer from CWI of CPP-651, CPP-653, CPP-609, CPP-1634, 1674, and CPP-661. The project reconfigured the existing fence to create an NE compound within INTEC to enclose these facilities. Completed facility modifications for CPP-651 included:

- Addition of a second exit with a new vestibule thereby correcting a Life Safety Code deficiency for personnel egress.

- Installation of LEU storage racks and associated shielding.

- Installation of a crane in the North Vault.

- Installation of a criticality detection alarm system.

- Construction was completed, new equipment was purchased and installed, all testing and startup of new equipment and systems was completed, and the facilities were turned over to operations. Communication missteps regarding availability of resources needed to complete the project through the readiness review resulted in a project shutdown; the issue was resolved and the project was finished before year's end. This storage will support additional storage at INL for the sodium-bonded fuel disposition product and continued transfers of EBR II driver fuel currently in the water storage pit at INTEC CPP-666, thereby satisfying the 1995 Governor's agreement between DOE-ID and the State of Idaho to remove all spent fuel from water storage by 2023.

MFC Electrical Distribution Loop A. The MFC Electrical Loop A project designed and is in construction of a ductbank system that will provide an electrical power loop, data, and communication capabilities for the northeast side of MFC. Loop A is designed to supply permanent power and fire alarm capabilities to the newly constructed IMCL and new electrical capabilities to the retrofitted Experimental Fuels Facility projects. In addition, Loop A has sufficient spare ductbank capacity to provide electrical, data, and communications capabilities for future buildings and backup generator power connections. The project started in June 2012 and completed in September 2012.

Experimental Fuels Facility (EFF): The Contaminated Equipment Storage Building (CESB) at MFC was re-designated as the EFF. The $\$ 2 \mathrm{M}$ conversion project included upgrades of the electrical, plumbing, and HVAC systems and addition of a HEPA-filtered exhaust system.

Sodium Separations System. INL completed a sodium separations system for use at the Fuel Manufacturing Facility at MFC. The system uses a high-temperature vacuum furnace to vaporize sodium before condensing it again in a collection vessel. Argon gas is used to keep the sodium inert. This INLdesigned and built system will enable continued cleanup of sodium waste resulting from historic uses of the highly reactive metal.

Remote Measurements Laboratory (RML). Multichannel detector measurement systems were modernized to handle the enhanced sample load and enable design, assembly and measurement after irradiation of special sample holders used to determine neutron energy and flux. Significant new instrumentation acquisitions include the GCxGCTofMS (LECO) and the UPLC-QTofMS (Dionex/Bruker Daltronics). 
National Security Test Range Upgrade. INL completed a significant capability enhancement to the National Security Test Range, installing and completing system testing of a flash x-ray system and flash $\mathrm{x}$-ray protective equipment. This new capability allows direct observation of highly transient events that cannot be imaged using conventional high-speed video techniques (e.g., real time imaging of bullets penetrating targets). The capability will enable better numerical modeling of the interaction of ballistics and explosives with armor materials and thereby improve designs of armor. Current customers who will benefit from this capability include SMC, Tank and Automotive Command (TACOM), and the Tank Automotive Research, Development and Engineering Center.

Radiological Spark Plasma Sintering (RSPS). INL's Center for Space Nuclear Research (CSNR) installed and is currently commissioning a unique, world class Spark Plasma Sintering (SPS) facility in CAES. A $10 \mathrm{kA}$ power supply and $222 \mathrm{kN}$ hydraulic press allows the SPS process to be performed on samples up to 3 inches in diameter and up to $2200^{\circ} \mathrm{C}$. This capability will enable diverse, multi-program research. Examples include high temperature nuclear fuels for space reactor and VHTR systems, secure and proliferation resistant radioisotope sources, irradiation resistant materials, high-density armor, and specialty irradiation target fabrication.

Energy Systems Laboratory (ESL). Construction of the new 90,000 $\mathrm{ft}^{2} \mathrm{ESL}$ was completed. The new lease facility, which will be occupied in October, houses new capabilities for the Advanced Energy Storage, Bioenergy, and Hybrid Energy Systems programs.

Research and Education Laboratory (REL). Construction started on the 148,000 $\mathrm{ft}^{2}{ }^{2}$ REL, which will collocate DOE program space with user facilities and serve as the gateway to the ATR National Scientific User Facility (NSUF) program. Occupancy is scheduled for FY14.

Table 3. Examples of other significant achievements.

\section{Technical Library Comprehensive Classification Review. INL completed the removal of all reports that were declassified in the 1970s as part of the Comprehensive Classification Review Program (CCRP). Library staff reviewed 1.25 million reports to accomplish the removal effort. Information Management is now working in conjunction with Safeguards and Security to change the status of the vault to that of a locked room, reducing costs and risks of maintaining a classified facility away from the main campus.}

Stress Corrosion Cracking Analysis. CAES developed stress corrosion cracking testing capabilities to address the cracking of structural materials in light water reactors. After establishing its expertise in determining stress corrosion cracking propagation rates over the past three years, the laboratory is now performing work for EPRI and the NRC and is collaborating with the University of Cincinnati on stress corrosion cracking mitigation techniques.
CAES Glovebox. The Materials Laboratory now houses a custom, stainless steel, 150-cubic-foot dual-access glove box. The glove box provides an argon negative pressure environment with less than 10 ppm oxygen maintained by an MBraun MB200G Atmosphere Regeneration unit. Sample prep equipment installed in the glove box includes a Buehler Low Speed Saw, a Buehler Minimet 1000 semi-auto polishing system, an Ohaus 310 gram balance, a Pace Technologies Vibratory Polisher, a manual hand polishing station, and a hot plate.

The EROB Human System Simulation Laboratory was completed. With the relocation of equipment from the HSSL at CAES and the addition of 15 digital benchboard panels, the completed facility is unique in the country, offering a full complement of digital panels that represent a complete control room, enabling research and experimentation that cannot be done elsewhere. This upgraded facility marks a significant turning point for the Human Factors group. 
CAES Radiochemistry Lab. CAES established a radiochemistry laboratory suited to research on advanced separations and measurement technologies for the molten salts used in electro-refining used nuclear fuel.
Advanced Vehicle Testing Activity. INL acquired a Ling Dynamic Systems model V8-640 shaker system to test automotive energy storage devices, particularly Lithium-ion batteries, to evaluate susceptibility to thermal runaway and overall robustness of design under normal or extreme driving conditions. 


\section{PARTNERSHIPS}

INL has engaged industry, government, and other stakeholders to initiate and maintain technology based partnerships and collaborations utilizing a wide range of partnership mechanisms.

TerraPower CRADAs. In FY12 INL and TerraPower LLC executed two CRADAs related to TerraPower's development of a travelling wave reactor concept. Both CRADAs leverage INL fuel design, analysis, fabrication and irradiation capabilities. The two CRADAs aggregate to a booked value of $\$ 2 \mathrm{M}$ funds-in, $\$ 7.8 \mathrm{M}$ in-kind from TerraPower, and $\$ 17 \mathrm{M}$ of government in-kind support provided through DOE's Fuel Cycle Technologies Program. The work is anticipated to continue through FY18.

Curtiss-Wright Corporation CRADA. INL and Curtiss-Wright signed a CRADA to develop and test a tailored material system suitable for specific components in nuclear reactor coolant pumps (RCPs) produced by Curtiss-Wright. The project will focus on development of an improved internal pump housing material.

Progress Energy CRADA. INL and Progress Energy signed a CRADA under which INL will assist Progress in modernization of their six nuclear power plant main control rooms over a 10-year period. This work will utilize the Human System Simulation Laboratory (HSSL) at the INL to produce full-scale mockups of the Shearon Harris and Brunswick nuclear generating station main control rooms and develop an end-state vision for modernized facilities in Progress' fleet of nuclear power reactors. Results of this research will be available to other nuclear plant operators and will be used to update the EPRI guidance documents on plant modernization.

Joint Fuel Cycle Studies with Republic of Korea. In the last quarter of FY11, INL obtained approval to initiate the Joint Fuel Cycle Studies (JFCS) between the United States and Republic of Korea (ROK). The JFCS is a 10-year collaboration to jointly explore fuel cycle options relevant to the ROK, including electrochemical recycling, used fuel storage, and corresponding safeguards activities. It is jointly funded by DOE and the ROK Ministry of Education, Science, and Technology and is implemented through a Cooperative Research and Development Agreement between INL, ANL, and the Korean Atomic Energy Research Institute (KAERI). Research, development, and demonstration activities were initiated in FY12.

Center for Advanced Energy Studies (CAES). CAES continued to grow and gain recognition as a collaboration center bringing INL and Idaho research universities together in a variety of partnerships with other academic institutions and industry across many energy related fields. State financial support for CAES was increased in FY12 as part of the Idaho Global Entrepreneurial Mission (IGEM) initiative and made a part of the base budget, raising the likelihood of continued state support in the future. FY12 research by CAES-centered teams ranged from anaerobic digestion to materials science to radiological material handling.

Japanese Joint Technical Exchange. Two Japan Atomic Energy Agency (JAEA) researchers from the Tokai Reprocessing Technology Development Center in Japan spent 8 weeks at INL as part of a joint technical exchange between the INL and JAEA. During their time at INL, Dr. Taguchi and Mr. Yamanaka worked with researchers the separation of actinides from lanthanides and investigation of thermodynamics and kinetics of separation processes. INL researchers Gary McDannel and Rocklan McDowell from the INL Aqueous Separations and Radiochemistry Department completed the exchange, spending 3 weeks at the Tokai Reprocessing plant.

Sophia Software Program. INL completed beta test licensing of Sophia, a fingerprinting tool for SCADA Systems. Deployment of Sophia is expected to enhance the security of the nation's critical 
infrastructure. INL executed 28 beta test licenses. Developed with funding from the DOE's Office of Electricity Delivery and Energy Reliability (DOE-OE), Sophia is a passive, real time tool for inter-device communication discovery and monitoring of the active elements in a SCADA system.

ATR NSUF User Week/MeV School. This year's MeV school was held in June at ORNL and INL. ATR NSUF worked with ORNL to host the event jointly. Participants spent a week at ORNL focusing on materials and a week at INL studying fuels.

Intellectual Property. INL employees submitted 88 Invention Disclosure Records in FY12. Patent applications totaled 24; 37 patents were issued to INL inventors. INL was authorized to assert copyright on seven copyrightable works. INL more than doubled their 3-year average of licenses executed with a total for the year of 175 licenses including 12 license option agreements, four patent licenses, and 159 copyright licenses (27 fee bearing, 132 non-fee bearing). INL recorded $\$ 1.5 \mathrm{M}$ in royalty receipts.

IGEM Initiative. The Idaho Legislature enacted Governor Otter's IGEM Initiative proposal to make permanent line item funding for CAES at \$2M per year, add \$2M per year to Higher Education Research Council (HERC) for research with high commercial potential and provide \$1M per year for statemanaged startup investments in new companies formed around technology developed in Idaho.

LINE Commission. In 2012, Governor Otter created the Idaho Leadership in Nuclear Energy (LINE) Commission. The Commission is charged with making recommendations to the Governor on policies and actions of the state of Idaho that will support and enhance the long-term viability and mission relevance of INL and the broader nuclear industry in the state. Much of the discussion has focused on whether updates are needed to the 1995 Settlement Agreement that recognize the significant progress made toward clean up and allow the flexibility for the lab to perform work critical to the nation's nuclear future. The Commission on which John Grossenbacher serves will present recommendations to the governor by January 2013.

International Reach. INL's international reputation continued to grow in FY12 as evidenced by interactions with more than two dozen countries around the world. In addition to the historical relationships in Western Europe, Asia and North America, INL also engaged in Slovenia, Mongolia, Malawi, Estonia, Chile, and Kuwait. Engagements drew upon the full gamut of INL technical program interests.

Agreements for Commercializing Technology (ACT). In FY-12, INL actively participated in proposing ACT to DOE, worked through implementation challenges and stood up INL's ACT program. Upon launch of the ACT pilot program, INL led the pilot laboratories in developing an inter-laboratory working group to increase the consistency of implementation across pilot labs and reduce costs by sharing work product. Working across organizations, Technology Deployment also stood up INL's own ACT program and organized an external review of the program that received favorable findings. INL requested approval of its ACT program in FY-12 and is awaiting DOE Contracting Officer approval, positioning INL to perform its first ACT agreement in FY-13.

CRADAs and Work for Others (WFO). In FY12 INL signed 18 new Cooperative Research and Development Agreements that include commitments of $\$ 12.8 \mathrm{M}$ of funds-in, executed 27 new non-federal WFO agreements worth $\$ 3.2 \mathrm{M}$ and recorded $\$ 126 \mathrm{M}$ of revenue from federal WFO transactions.

Critical Materials Hub. INL established a strategic partnership on a leadership class Critical Materials Hub team and submitted a competitive proposal to the national DOE (EERE) call. INL capability deployment is focused on separations science and advanced materials that are also critical elements of advanced fuel cycle R\&D. By applying this capability to strategic materials markets, INL is leveraging our recognized capabilities in nuclear science to address another top DOE and industry priority. In addition, INL is working directly with Molycorp, the U.S.'s only domestic provider of rare earth materials via a work for others agreement in the development of novel extraction approaches and improved detection of rare earths in their chemical processes. 
Energy Storage Hub. INL established a strategic partnership on a leadership class BES Energy Storage Hub proposal. We teamed with NREL, MIT, Harvard, Siemens Corp., XL Hybrids, FastCap Systems, Liquid Metal Battery Co., among others. INL will provide materials research and screening, testing, modeling, and diagnostic/structural analysis support.

Technology Based Economic Development. INL's Technology Based Economic Development Program works to foster an entrepreneurial culture through many relationships and engagements throughout the Idaho economic development community. In FY12 INL:

- Supported 25 technical assistance projects making more than 1,000 hours of INL technical expertise available to small companies and local government.

- Supported 20 teams of university students and innovators taking part in the TechLaunch 9.0 event held in Boise, Idaho. TechLaunch is a business pitch contest and startup workshop held annually since 2004.

- Through its contract with TechConnect, provided 55 companies and individuals with assistance related to SBIR/STTR and other financial assistance programs.

- Provided personnel to serve on the boards of more than 10 economic development organizations across the state, including the Idaho Innovation Council, Bannock Development, and Grow Idaho Falls.

Table 4. Examples of other significant partnerships.

Capital Asset Planning. Under a Work For Others agreement, IM worked with the General Services Administration (GSA) to implement a Capital Asset Planning module within GSA's web-based Federal Aviation Interactive Reporting System (FAIRS). The module provides GSA, Office of Management and Budget (OMB), and other federal agencies with a standardized approach to the development of business cases for aviation assets.

Mountain West Water Institute hosted the Western States Water Council (WSWC) fall meeting in Idaho Falls. The WSWC, an organization representing the Governors of 18 western states, works closely with the Western Governors' Association on water policy issues of concern to the governors

Spectrum Sharing Technical Workshop. INL partnered with telecommunications carriers, OEMs, NTIA, FCC, DOE, and DoD to formulate and implement a technical action plan for spectrum sharing research, experimentation, and performance validation in the $1755 \mathrm{MHz}$ to $1780 \mathrm{MHz}$ spectrum. The focus is on commercial LTE technologies and incumbent DoD technologies.
Origin Oil. INL entered a CRADA with Origin Oil to create and set industry standards for algal biomass. The emergence of industry standards can advance the algal biofuel marketplace and help create the economics that make algal biofuels a competitive alternative to petroleum. This is important because DOE- Energy Efficiency and Renewable Energy (EERE) is starting an algae to fuels program, which will support industry-lab partnerships.

Collaboration with Idaho Department of Transportation (IDT). INL and the IDT signed a contract under which IDT will perform condition assessment surveys of INL primary roads using IDT's state of the art pavement inspection equipment.

EPRI CRADA. INL executed a CRADA with EPRI to demonstrate and analyze feasibility of supplementing and substituting biomass for coal in electrical utility boilers. The CRADA involves analysis of sustainable biopower co-firing, biomass processing, assembly and supply, and combustion tests. INL is supporting EPRI with the development of feedstock for possible cofiring tests in Alabama and Oregon. 


\section{PERFORMANCE}

FY12 performance in operations was marred by several significant events in nuclear facilities. INL has gone to great lengths to understand our weaknesses and take corrective and continuous improvement measures that will lead to sustained operational excellence in all that we do.

Occupational Injury/IIlness Safety Performance. FY12 was the safest on record for BEA employees since the inception of INL. During FY12, more BEA employees completed their respective workdays safely than during any of the prior years. During this time period, 28 BEA employees sustained injuries serious enough to be classified as OSHA Recordable, resulting in a Total Recordable Case Rate (TRCR) of 0.75 . This represents an improvement of $37 \%$ compared to the FY04 baseline, and is over $23 \%$ better than FY11. Of the 28 OSHA Recordable cases BEA employees have incurred, 12 have also resulted in Days Away Restricted or Transfer (DART), resulting in a DART Case Rate of 0.32, This represents an improvement of over $47 \%$ compared to the FY04 baseline, and is almost $40 \%$ better than FY11. Of the 19 major organizations comprising BEA, 10 completed FY12 without incurring an OSHA Recordable injury or illness. Twelve of the 19 major organizations did at least as well or better, from a TRCR perspective, in FY12, as compared to FY11. Sixteen of the 19 major organizations did at least as well or better, from a DART Case Rate perspective, in FY12, as compared to FY11.

\section{Safety - How are we doing?}

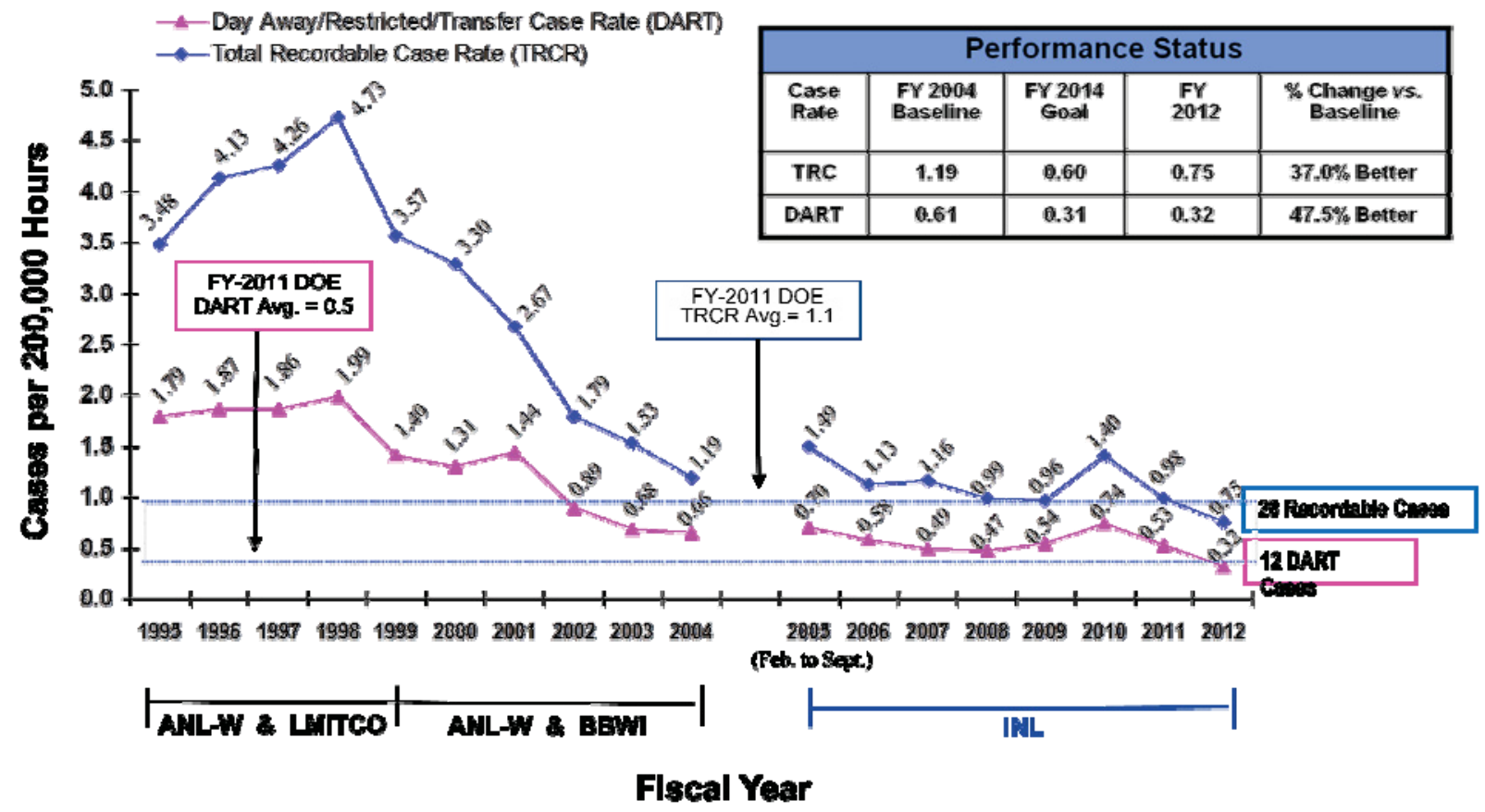

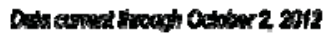

Figure 1. Safety record at INL. 
ISMS and INL Sustained Operational Improvement. Two major initiatives were rolled out in FY12 to address improvements in work control and the radiological control program: the Sustained Operational Improvement Initiative and the Radiological Control Road to Excellence Plan (RTE). They focused on Organizational Effectiveness, Work Management/Conduct of Ops, Radiological Control, and Critical Assurance Activities to improve the effectiveness of the INL ISMS. All of the associated corrective actions and improvement opportunities are on schedule in both initiatives. INL senior management routinely reviews the progress of these activities and it continues to be a top priority.

Contractor Assurance System (CAS). An independent review of the CAS conducted late in the fiscal year by experts drawn from other DOE facilities concluded that "processes, tools, methods and practices are effectively implemented, risk-informed, and result in proactive identification and resolution of issues." According to the review team, credible, actionable information is systematically obtained and used to manage and improve performance. Significant progress in the maturation of CAS, buy-in and understanding of the system and its tools (e.g., ICAMS), and modeling of desired behaviors at all levels of the organization were observed. Having noted the long-term improvement, the review team recommended a number of areas of focus going forward:

- Continue to shift paradigm from event-driven to performance improvement (event response versus event prevention)

- Emphasize tools that are working, jettison those that are not effective

- Involve employees at all levels in system design, evaluation, and operation

- Continue use of graded approach keyed to facility/activity risk profile.

MFC Stand-down. INL Leadership initiated an extensive continuous improvement effort to address previously identified weaknesses in our systems of controls during the first quarter of FY12. Work load and complexity increased. In April, a shutter shield drop event at HFEF and an incident of cutting into a live electrical wire at ZPPR indicated that the ongoing improvement efforts were not achieving objectives as quickly as desired. On April 18, 2012, leadership issued a stand-down for all discretionary work at MFC and took steps to implement a step change improvement in engineering, administrative, and human performance controls at MFC. Extensive measures were taken to ensure employees understand and commit high standards for nuclear operations and radiation control. Stringently controlled processes for resuming maintenance and research activities were put in place. Since the stand-down began, additional training and verification steps were added to the recovery plan and will continue while working toward full operational status. All original objectives have been met and MFC is demonstrating accountability and engagement across all research, facility, and functional support groups. Radiological control corrective actions for MFC Response Plan were completed and radiological work resumed on June 4.

\section{MFC Accomplishments.}

- Implemented a step-change in standards and conduct of work at MFC through strengthened commitment to ownership and accountability

- Implemented a mentoring program and strengthened management observation program

- Completed 75 Level-2 milestones and other key activities, including:

- Began receipts of EBR-II fuel for multi-year treatment campaign, using new haul road

- $\quad$ Exceeded Site Treatment Plan (STP) 2.0 cubic meter milestone by treating 3.3 cubic meters of INL backlog STP waste

- Recovered and decontaminated ZPPR facility from Nov. 2011 event to support Homeland Security training exercises to support NA40 and Homeland Security training exercises

- Completed implementation of Documented Safety Analysis for the Material Security \& Consolidation Complex (MSCC) at INTEC 
- Completed 29 RH-TRU retrievals at the Radioactive Scrap \& Waste Facility (RSWF)

- Successfully completed analyses to support our Atomic Energy of Canada, Limited (AECL) Canadian CRADA

- Successfully installed and tested IAAC decanning box and MAGB environmental control systems.

- Progress continued toward upgrading the Documented Safety Analyses (DSAs) for nuclear facilities at MFC:

- Work associated with implementing the DOE-approved DSAs for the Analytical Laboratory (AL) and Fuel Conditioning Facility (FCF) continued.

- Progress was made on resolution of DOE comments on the HFEF and Neutron Radiography Reactor (NRAD) DSAs.

- Significant improvement in the ZPPR DSA allowed resumption of programmatic work execution in ZPPR. Further work is needed to produce the final upgraded DSA.

ATR Accomplishments. Supported overall execution of customers' priority experiments by:

- Completing irradiation of NR Experiments SE-191, SW-185 supporting NR type-N core designs Establishing an Equipment Reliability Index measurement and realizing a sustained increase in the index from an established baseline

- Delivering the Naval Reactors Test Reactor Cask (TRC) maintenance stand and commencing design modifications on the TRC

- Completing additional upgrades to the ATR to support increased capabilities and improve plant reliability

- Safely planning and executing high-risk radiological work to address the $200 \mathrm{Rem} / \mathrm{hr}$ hotspot on the M-4 heat exchanger during the seismic upgrade project

- Completing assembly and change-out of the Center Flux Trap Baffle (CFTB) with redesigned N-16 tubing to mitigate incompatible material driven failures of the tubes

- Reactivating Loop 2A Center In-Pile Tube to provide additional capabilities to support the needs of the EPRI customer

- Completing installation of a newly designed Water Power Calculator to replace the existing obsolete system;

- Continuing execution of Core Internals Change (CIC) Out planning

- Hiring key support resources for planning and execution of CIC

- Progressing in the training and qualification of seven shift technical advisors at ATR, numerous key MFC operators and technicians, and plans for hiring of ATR experiment representatives.

ATR Cask Hotspot Event. On June 12, 2012 during cask leak testing, in preparation to ship irradiated cobalt (Co) capsules in the GE 2000 cask, unexpected high radiation levels of $4000 \mathrm{R} / \mathrm{hr}$ on contact were detected. The potential for personnel exposure was minimized by the radiation control technician responding quickly in accordance with criteria contained in the RWP and as briefed prior to the work commencing. Collective dose was less than 200 mrem because of use of robotics, extension tools, and mock-up. ATR programs developed recovery plans, procedures, and equipment to safely isolate and recover the hotspot; trained personnel and conducted mock up activities on the recovery efforts; and safely isolated and recovered the hotspot allowing the impacted activities to resume after approximately a 1 -month delay. This event resulted in an operating performance lower than planned late in the fiscal year. 
Office of Professional Responsibilities (OPR). OPR was established to provide an enterprise approach to workplace concerns. It establishes a single entry point for all INL employee workplace concern programs and is expected to improve effectiveness, consistency, and timeliness in resolving workplace concerns.

Sustainability. INL received the first Department of Energy Management Award to recognize the exemplary sustainability program team for outstanding contributions to energy, fuel, and vehicle fleet management and associated cost savings at INL facilities. INL committed $\$ 1.5 \mathrm{M}$ of strategic investment funds to the strategic initiatives on sustainability and sustainment.

- The FY12 Strategic Sustainment Initiative utilized the DOE-NNSA Roof Asset Management Program (RAMP) to accomplish 21,865 $\mathrm{ft}^{2}$ of critical roof replacement with roofing that meets DOE

"Cool Roof" requirements, exceeding the PEMP target of 20,000 $\mathrm{ft}^{2}$. An additional 85,000 $\mathrm{ft}^{2}$ of cool roof area was installed as part of new construction and modifications.

- All FY12 Strategic Sustainability Initiative investments were geared toward the Guiding Principle mandate, PEMP targets, and the OMB Scorecard. Strategic funding was split between R\&D and F\&SS, with R\&D focused on "Targeted Energy Management Toolset for Comfort and Savings Based on Advanced Computational Intelligence" and F\&SS funds focused on facility upgrades.

- Received the Post Project Measurement and Verification Report for the MFC Energy Savings Performance Contract (ESPC) validating that savings are being achieved, and made the post project and Year 1 contractual payments. INL provided technical and project management-related support to DOE-ID and AMERESCO with development of ESPC Project 3 for CFA and ATR Complex. Currently, INL energy intensity is down over 7\% compared to the FY03 baseline.

- Landfill waste diversion is $26 \%$ of total generated landfill waste. GHG reduction calculations indicate a $24.1 \%$ reduction in Scope 1, a 28.5\% reduction in Scope 2, and a $3.3 \%$ decrease in Scope 3 GHG emissions for FY11 as compared to the FY08 baseline. The total combined net anthropogenic and biogenic emissions are calculated at a 7.8\% reduction in FY09, an 8.5\% reduction in FY10, and a $21.3 \%$ reduction in FY11 as compared to the baseline. FY12 results are not yet available.

- Upgraded lighting, water fixtures, control systems, and operating equipment were installed, reducing energy and water usage at the Idaho Falls REC.

Earned Value Management System (EVMS). Capping a year of work and various reviews, INL was notified by DOE that we had "...successfully demonstrated compliance of (our) Earned Value Management System (EVMS).” DOE O 413.3B requires EVMS certification to pursue future projects $(>\$ 100 \mathrm{M}$ cost) that are necessary for future growth and meeting long-term goals.

INL Leads the Way in Going Google. As part of the High Performance Workplace Initiative, Google Apps for Government was successfully rolled out to INL, the first DOE national laboratory to move to the "cloud" with a Federal Information Security Management Act (FISMA) compliant solution. Future cost reductions and productivity gains figured into the decision to move to Google. All virtual forms previously accessible through Lotus Notes were successfully migrated to the new web-based environment.

DOE-VPP "Superior Star" Award. To qualify, a site must achieve injury/illness incidence rates and lost workday injury/illness rates at least $50 \%$ below the Bureau of Labor Statistics national average for relevant SIC/NAICS code, meet annual DOE-VPP goals, and demonstrate strong involvement in the VPPPA, VPP mentoring, and outreach.

Resource Management and Reporting (RMR). The RMR Strategic Investment was completed with a successful data migration. All FY13 work scope planning was done utilizing the new database for schedule development. 
HQ Review of RHLLW Disposal Project. An independent project review (IPR) of the readiness of the RHLLW Disposal Project to proceed resulted in Acquisition Executive (AE) approval of Critical Decision (CD)-2 and conditional approval of CD-3. The IPR identified six concerns that can be readily addressed to support AE approval, 10 opportunities for improvement, and 10 positive observations. Follow on correspondence from the team commended the INL Team's work in developing the performance assessment (PA). The DOE LLW Federal Review Group determined it to be an exemplary document that will be used as a prototype in the future for evaluating compliance with a pending DOE order on radioactive waste management.

Table 5. Examples of other operating performance accomplishments.

\section{Security Awareness and Training has worked with the Incidents of Security Concern Program, OPSEC, Physical Security Officers, Cyber Security, and many other groups to assist the laboratory in reducing the incidents of security concern by $50 \%$ when compared to FY11. \\ Information Management/Process \\ Upgrades. INL upgraded the existing Electronic Change Request (eCR) process to enable paperless submission of change requests for electronic and hardcopy documents. An inspector certification database which interfaces with TRAIN replaced the legacy paper system.}

Power Supply Reliability. Uninterrupted power systems at INTEC and MFC are being replaced and several access control systems are being upgraded or replaced.

Bus Fleet Upgrade. The INL fleet added 52 new leased MCI J coaches with transmissions designed specifically for INL geography and operating conditions; they are Wi-Fi equipped and should deliver $\sim 15 \%$ better mileage than the white buses.

\section{Procurement Evaluation and Re-} Engineering Team (PERT). A periodic PERT review by DOE cited no significant concerns. The report cited SCM's strategic alignment, advanced planning, and leadership and participation on the Contractor Supply Chain Council (CSCC), PERT, and Integrated Contractor Purchasing Team (ICPT).
Security System Investments. Replacing 30-yearold clearance information system with digital cameras sitewide. Installed a non-intrusive inspection system for radiographic vehicle scanning at MFC. Installed all security systems necessary for INTEC 651 and ESL.

The ATR Complex Information System has been installed at TRA-616, -649, -653, -657, -658, and 1608 . This group of programmable television screens will be used to keep employees informed of operational status, weather bulletins and other important workplace information.

Federal Electronics Challenge (FEC): BEA received the 2012 FEC Silver Level Award for FY 2011 activities in the procurement and management of electronics. INL has received the FEC award each year since 2007.

Idaho Computing Consortium (ICC) Three Idaho universities are active participants with INL in the University Network. The latest addition to the University Network is a 135-node Dell supercomputer on loan to ISU.

Successful EMS Re-registration. INL's thirdparty auditor, NSF International Strategic Registrations, conducted a triennial registration audit of the Environmental Management System (EMS). The audit confirmed that all functions required by ISO 14001 standard are in place and effectively implemented 


\section{KEY PERFORMANCE ISSUES/CHALLENGES}

FY12 experience brought to light a number of performance shortcomings in individual INL systems and organizations which resulted in recovery or improvement plans. It is understood throughout the laboratory that INL must continue to push itself to higher performance levels in the near term and must never grow complacent about improving performance.

The New "Normal" at MFC. Although INL has taken aggressive actions to improve safety and work performance at MFC, going forward, a key challenge is sustaining the gains made to reset operations to a new "normal." Many improvements from the stand down and ZPPR corrective actions have not had time to develop fully. INL must focus on developing a mature self-critical organization with the following characteristics:

- Mission is accomplished safely, with high quality and efficiency.

- $\quad$ MFC operates as one team with shared goals, accountability, and ownership for the mission.

- Work is effectively integrated to build confidence in work acceptance and execution (planning, cost estimating, performance, and scheduling).

- Efficiency has been gained without risking safety.

- The quality and competence of staff has improved.

- MFC has developed and nurtured an environment supportive of research, respectful of risks, and objective in discriminating between activities that can and cannot be engineered.

- $\quad$ MFC has fully and effectively integrated and implemented corrective action plans and paths to excellence.

- $\quad$ MFC has implemented an effective financial model that supports the facility's mission.

Sustained Operational Excellence. In light of FY12 operational shortcomings (e.g., ZPRR Pu incident, high external dose event, electrical near misses), much effort was placed in achieving sustained excellence in operations. In FY13, INL must continue to apply and implement institutional improvements in operations (PLN-4030): Integrated Safety Management (ISM) at the activity level (i.e., proper identification and documentation of hazards during work planning and adequate control while work is being executed); operational contractor assurance; conduct of operations; and leadership and supervision.

Project Execution. Although FY12 was a year with many project successes as noted in other sections of this report, a number of highly visible projects (e.g., Restoration of ATR Loop 2A Materials Security and Consolidation Project) experienced issues that eroded customer confidence:

- Weaknesses in documented objectives for project, including definition of operations turnover.

- Lack of clear project sponsorship.

- Ineffective change control of project baselines.

- Breakdown in communications and project monitoring and reporting, external and internal to projects.

- Ineffective integration of program and operations with project elements.

- Breakdown in project oversight and resourcing.

INL expects to make improvements in advanced project planning, institutional project assurance and reporting, turnover planning, and resource management, and reporting to address these performance weaknesses. 
Fiscal Challenges. The prolonged federal budget challenges in the years ahead will constrain direct and indirect investments while necessitating additional workforce reductions. The laboratory was challenged to manage through these dynamics in FY12 and must better prepare and be more effective in its management practices to avoid negatively impacting programs. The 2012 Laboratory Plan and 2014-2023 Ten Year Site Plan, which are well integrated, provide the foundation to respond as fiscal events unfold throughout the year. It is expected that there will be continuous external pressure to reduce discretionary costs (e.g., travel, fleet, management, and administration) and right size the laboratory consistent with its mission and capabilities; this includes addressing gaps in skill mix and training level of the workforce.

Thought Leadership. The unfolding fiscal challenge will place a greater burden on INL's role as a Technical Integrator and "thought" leader for NE. INL must assist NE in development of a sustainable long-term strategy for nuclear energy research and development in the U.S, consistent with national priorities and fiscal realities. This integration must develop three elements in parallel: construction of needed facilities; development of experimental, modeling, and human capabilities; and definition of focused strategic goals.

Relevance and Impact of Science and Engineering. The role of INL as the national nuclear capability will receive greater scrutiny as stakeholders look for relevant and impactful scientific and engineering outcomes from the laboratory. The laboratory will be measured by its ability to deploy and demonstrate technology that advances U.S. competitiveness, including the use of newly enacted technology transfer mechanisms, such as, Agreements for Commercializing Technology (ACT).

Cross Directorate Integration. To achieve greater efficiency and impact, INL continues to focus on leveraging capabilities and resources across directorate and program lines. For example, work on the Critical Materials Hub focuses on separations science and advanced materials that are also critical elements of advanced fuel cycle R\&D. In applying this capability to strategic materials markets, INL can leverage recognized capabilities in nuclear science to address another top DOE and industry priority while enhancing the capability base needed to advance our nuclear fuel cycle R\&D.

State Dynamics. INL will continue its work with the State of Idaho to assess the impact of the Blue Ribbon Commission Report on its current policies/agreements while supporting the LINE Commission from a technical standpoint. 


\section{CONCLUSIONS}

INL, the recognized lead national laboratory for nuclear energy, continued on the path to international preeminence during FY12, leveraging synergistic world-class multi-program capabilities to address key DOE strategic objectives, achieve new partnerships, and earn further recognition in the research community. The reputation of the laboratory, its facilities, and its research staff continued to grow with industry as well as internationally. A number operational, fiscal, and managerial challenges clouded INL progress during the year, but led to renewed commitments to excellence and strengthened systems and processes.

- INL technical collaborations with the nuclear industry are increasing

- The number of organizations collaborating in the use of specialized facilities is growing

- INL interactions involve a growing number of foreign entities

- INL had its best year yet in occupational injury and illness performance, security performance, and licensing revenue

- Advocacy for INL and its mission is strengthening within Idaho and on the national level

- INL contributions to educating the workforce of the future continue to grow in size, reach, and reputation.

INL continues to add new facility, equipment, and human resources that strengthen its ability to earn the designation of a world-class laboratory. 


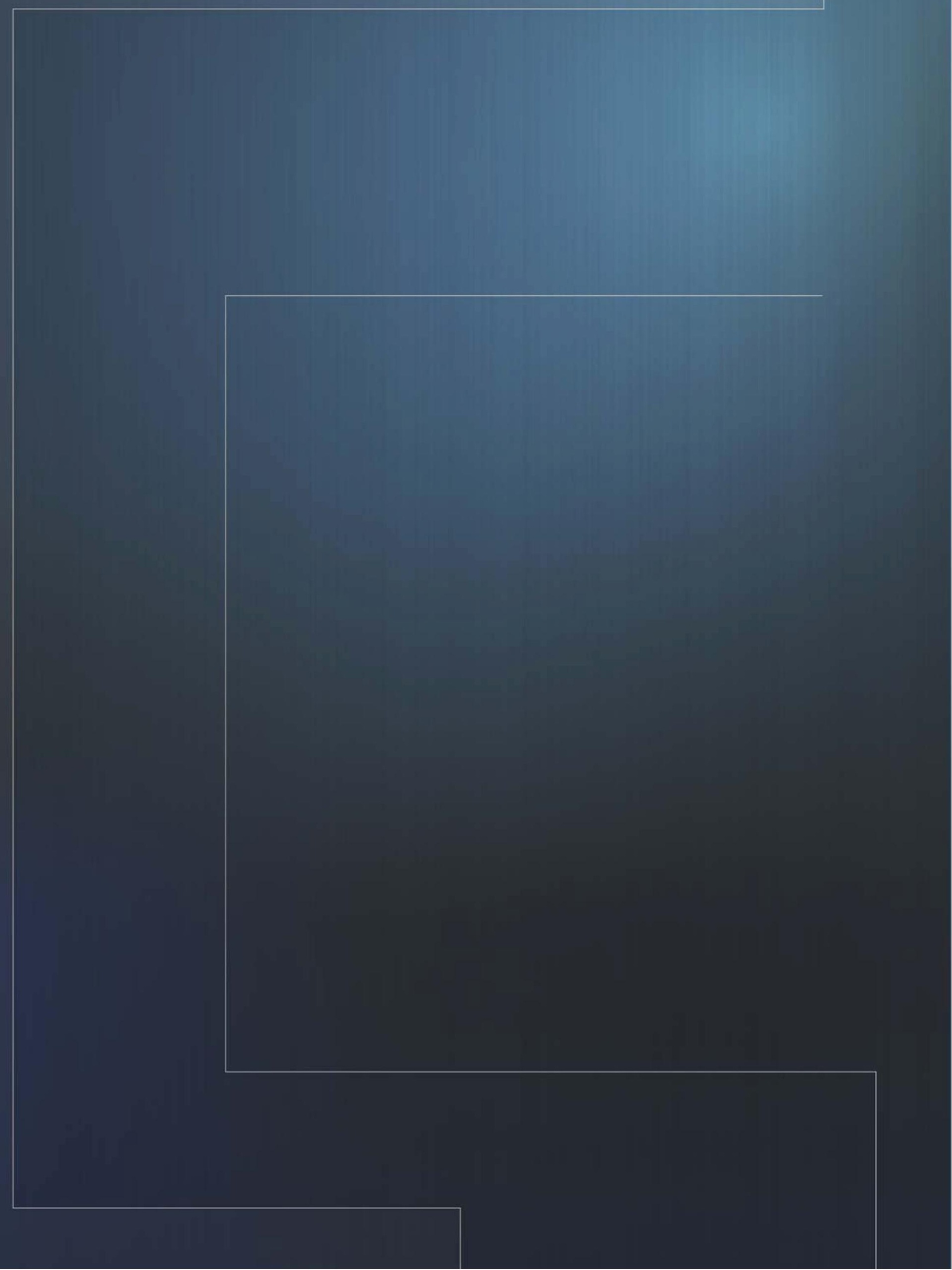

